\title{
Full-Scale Municipal Sludge Pyrolysis in China: Design Fundaments, Environmental and Economic Assessments, and Future Perspectives
}

Hongxi Luo ${ }^{1,2,3}$, Fangwei Cheng ${ }^{4 *}$, Bin $\mathrm{Yu}^{2}$, Lei Hu${ }^{2}$, Junfa Zhang ${ }^{2}$, Xiangpeng $\mathrm{Qu}^{2}$, Hai Yang ${ }^{2}$, Zhen Luo ${ }^{2}$

${ }^{1}$ EnviPro Design LLC, Charlottesville, Virginia, 22903, United States.

${ }^{2}$ Wuhan Pro-Envi Tech Co., Ltd, Wuhan, Hubei, 430062, China

${ }^{3}$ Department of Chemical Engineering, University of Virginia, Charlottesville, Virginia, 22904, United States.

${ }^{4}$ Andlinger Center for Energy and the Environment, Princeton University, Princeton, New Jersey, 08544, United States.

*corresponding author:

Email: fangweic@princeton.edu

\begin{abstract}
The increasing amount of municipal sludge in China requires safe and effective management to protect human health and ensure environmental sustainability. Pyrolysis is a thermochemical process that that decompose organic matter at elevated temperature and under anaerobic conditions, and it has attracted an increasing attention in sludge treatment in the recent years. However, comprehensive environmental and economic assessment of sludge pyrolysis in China's context is rare, due to the small quantities of fullscale sludge pyrolysis plant. In this paper, we applied our design and operation parameters of full-scale sludge pyrolysis plants to generate the material and energy consumptions of the pyrolysis system under various of conditions, including sludge organic content and moisture content, system size, system energy distribution, and whether or not heat substitution is applied. Life cycle assessment and techno-economic assessment were then applied to investigate the environmental and economic performance of the system
\end{abstract}


Our results demonstrate the significant environmental and economic impacts associated with sludge properties and system size. Generally, sludge with higher organic content and lower moisture content requires less natural gas consumption, which leads to a simultaneous improvement of the system environmental and economic performance. The system economic performance is more sensitive to the system size, and centralized sludge handling using a larger pyrolysis is more economic favorable. In the most ideal case, the average global warming potential and minimum sludge handling price of sludge pyrolysis could be as low as $-32.5 \mathrm{~kg} \mathrm{CO}_{2}-\mathrm{Eq} / \mathrm{t} \mathrm{DS}$ and $188.8 \$ / \mathrm{t} \mathrm{DS}$, respectively. Based on these results, we discussed the pathways that could be taken to further optimize the environmental and economic performances of the pyrolysis system.

\section{Introduction}

Municipal sludge is a byproduct of municipal wastewater treatment, and it contains various of hazardous pollutants, e.g., heavy metals and toxic organic compounds, and harmful microbes, e.g., bacteria [1-3]. If handled inappropriately, sludge could become a great threat to human health and cause severe environmental issues $[4,5]$. As of 2019, China is estimated to have 5476 municipal wastewater treatment plants (WWTPs) in normal operation, and these WWTPs would produce 39.04 million ton of sludge (with $80 \%$ water content) each year [6]. Among all the sludge being produced, a decent portion of sludge, i.e., around 50\%, was managed or handled by direct land application and landfilling [6, 7]. However, direct land application and landfilling generally lead to two problems. First, the hazardous pollutants and harmful microbes are not fully stabilized, so they would enter the ecological cycle or the food chain. Next, these two methods, especially landfilling, would occupy lands that could be otherwise used as agricultural lands or residential lands [8]. Therefore, other sludge treatment techniques, such as anaerobic digestion and incineration, have been considered as alternatives to land application and landfilling in China. Anaerobic digestion has been widely used by the WWTPs in European countries [9], 
yet its share in China's sludge treatment market is much lower. In fact, around 50 anaerobic digestion plants have been built in China, and only about 20 are still under normal operations [10]. The major challenge that anaerobic digestion faces in China arises from the sludge properties in China. Compared to the sludge in European countries, the sludge in China generally has low organic content, e.g., 30\%-60\%, and the low organic content inevitably leads to low methane yield and low biogas concentration during anaerobic digestion [11]. As such, the process energy efficiency is much lower in China than in European countries. Furthermore, the processing time for anaerobic digestion is long, and this drawback also makes it less attractive in handling China's sludge, which often comes in large volume. Incineration is effective in stabilizing sludge and reducing its volume, and incineration also has the potential for energy output [12]. Hence, incineration is an attractive alternative to landfilling, especially for well-developed cities with limit lands. Overall, incineration has around $26.7 \%$ of share in sludge handling [6], and is recommended by Ministry of Ecology and Environment (MEP). However, miscellaneous emissions, e.g., dioxins and $\mathrm{NO}_{\mathrm{x}}$, and ashes from incineration, e.g., oxidized heavy metal, are still hazardous pollutants/wastes, and they need to be treated or stabilized appropriately [13]. These sludge handling strategies, though wellestablished, are still not sustainable enough, so finding more environmentally friendly sludge treatment methods that still possess the key merits of incineration, e.g., rapid sludge volume reduction, becomes an urgent need for the sludge handling industry in China.

Pyrolysis is a technology that decompose organic matter at elevated temperature and under anaerobic conditions [14-16]. When pyrolysis is applied in sludge treatment, its thermal treatment nature guarantees the rapidness and effectiveness of sludge volume reduction, and its anaerobic nature greatly reduces the formation of hazardous pollutants/wastes, e.g., dioxin, NOx and oxidized heavy metal [17, 18]. Furthermore, the pyrolysis process could transform sludge into a valuable biochar-like product, pyrolyzed sludge (or carbonized sludge in some studies), and the pyrolyzed sludge could either be used as an 
alternative fuel to generate heat and electricity or used as a soil amendment to promote plants growth and sequester $\mathrm{CO}_{2}[15,19]$. The feasibility of full-scale sludge pyrolysis has been verified by Japanese companies in late 1990s, and they applied pyrolyzed sludge as an alternative fuel for energy production. When comparing to sludge incineration-based power generation, a reduction in the total emissions was observed in the sludge pyrolysis-based power generation $[20,21]$. While sludge pyrolysis is a wellestablished technique, it has only been applied in sludge treatment in China for 12 years. Our team built the first pilot-scale sludge pyrolysis plant (10 t $80 \%$ moisture feed sludge per day) in Tangxun Lake (Wuhan, Hubei) in 2009, and the first full-scale plant (60 t $80 \%$ moisture feed sludge per day, still operated by us) in E'zhou (Hubei) in 2014. Instead of applying pyrolyzed sludge as an alternative fuel, we focused on the soil application of the pyrolyzed sludge, as the heating value of pyrolyzed sludge is lower in China. With China's pledge to achieve net-zero by 2060, the climate change benefits, e.g., $\mathrm{CO}_{2}$ sequestration effects, arising from pyrolyzed sludge could be beneficial to facilitate the deep decarbonization, and those benefits would turn pyrolysis into an even more attractive technique for sludge treatment $[15,22]$.

To fully reveal the potential of pyrolysis as a sludge handling technique, comprehensive environmental and economic analysis on the performance of full-scale sludge pyrolysis is required. Life cycle assessment (LCA) and techno-economic assessment (TEA) are effective approaches that evaluates the environmental and economic performance associated with products, processes, and systems [23, 24]. LCA and TEA studies of municipal sludge management in have been extensively studied in China's context during the past ten years. However, only a few of them have brought pyrolysis into comparison, possibly due to the small quantities of sludge pyrolysis plant. For example, Wang et al. developed pyrolysis models lab-scale data, and this process was compared with mono-incineration, co-incineration and direct landfill [25]. Their results showed that pyrolysis was overall the most preferrable sludgehandling option. Cao et al. carried out a comparative LCA on pyrolysis, and their results suggested 
negative $\mathrm{CO}_{2}$ emissions could be achieved [26]. More recently, Cheng et al. developed an integrated LCA and TEA framework that quantifies the environmental and economic performance of biomass pyrolysis systems with varying feedstock properties and operating conditions [15]. However, significant differences in the system environmental and economic performance were observed when we compare the LCA and TEA results from these works to the data we obtained from the full-scale plant in E'zhou. More specially, these studies generally overestimate the environmental and economic performance of the sludge pyrolysis system. Such overestimation is a caused by the general lack of understanding of the pyrolysis system at full-scale and the use of pre-determined parameters rather than the parameters used in the design and operation of the full-scale pyrolysis plant. As an overall result, the predictions from these pioneer studies are generally less representative for full-scale sludge pyrolysis system in China, and more representative analysis is thus required.

The goal of this study is to provide representative and comprehensive environmental and economic evaluations for large-scale sludge pyrolysis system in China. This goal was further divided into several specific objectives. First, we presented a detailed process description and discussed several critical fundaments of the full-scale pyrolysis system to facilitate the understanding of such system at full-scale. Next, we incorporated the design and operation parameters and economic estimations for full-scale sludge pyrolysis plants to evaluate the environmental and economic performance of sludge pyrolysis systems under varying conditions, including different sludge feed in moisture content, organic content, system size of the plant, as well as the system energy distribution. In other words, the parameters used in the LCA and TEA of this study are identical to those we used to design and operate the full-scale plant in E'zhou. Finally, perspectives on further optimizing the environmental and economic performance of pyrolysis system were given based on the LCA and TEA results. 


\section{Methods}

\subsection{Process Descriptions}

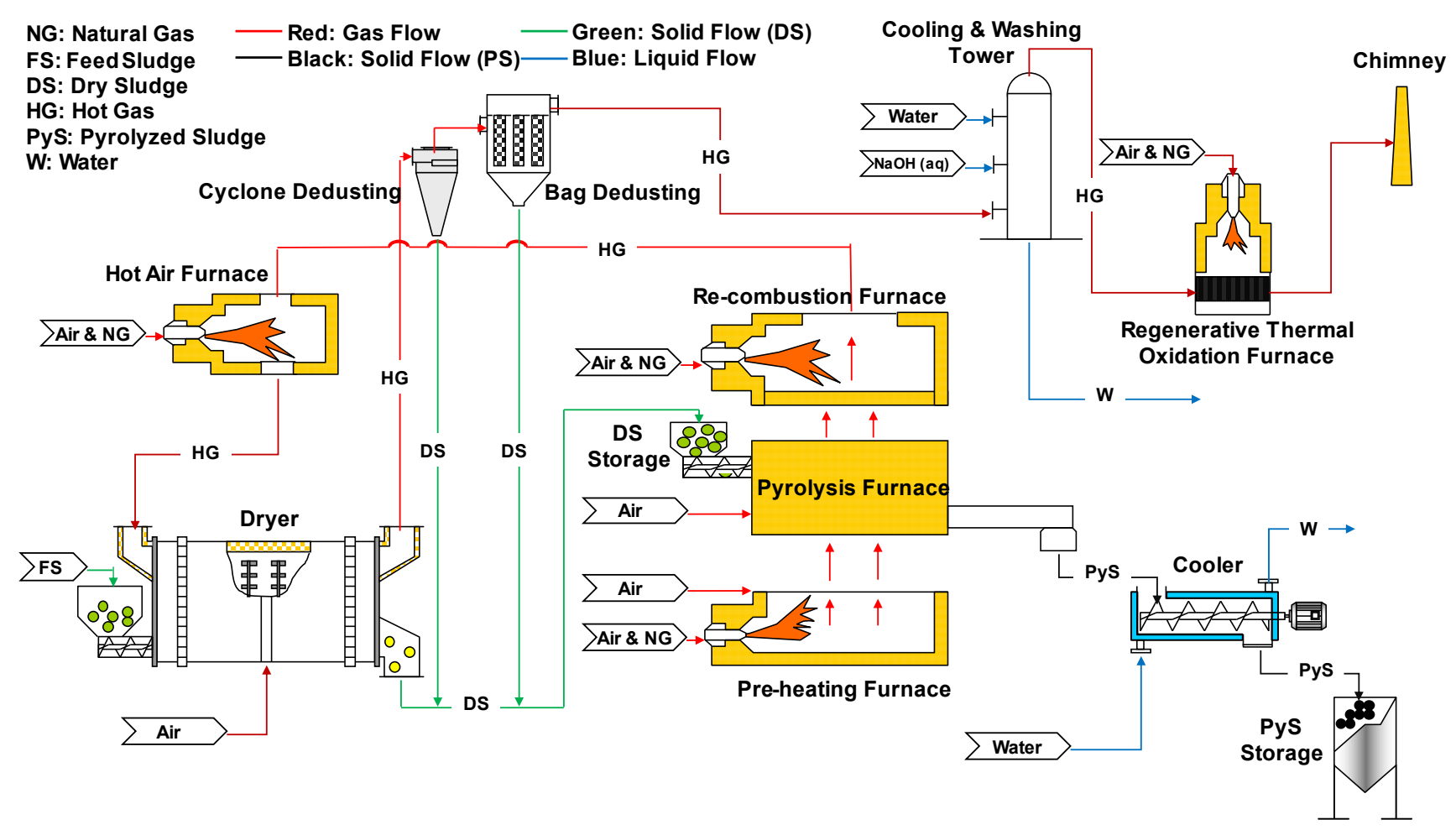

Figure 1. Illustration of the full-scale municipal sludge pyrolysis system evaluated in this work. A picture of the full-scale plant using this design (E'zhou, Hubei) is included in the Supporting Information.

The full-scale municipal sludge pyrolysis system evaluated in this work was illustrated in Figure 1. This sludge pyrolysis system is built in a wastewater treatment plant (WWTP). Feed sludge (FS), containing $80 \%$ moisture, is directly taken from the WWTP and sent to a hot-gas (HG) powered dryer first. The $\mathrm{HG}$ enters the dryer at $850{ }^{\circ} \mathrm{C}$, flows concurrently with the FS stream to remove most of the moisture from the FS, and leaves the dryer at $200{ }^{\circ} \mathrm{C}$. The drying process reduces the sludge moisture content to $20 \%$, and the resulting dry sludge (DS) leaves the dryer at $80{ }^{\circ} \mathrm{C}$. The flow of the $\mathrm{HG}$ stream will be described first, followed by the flow of DS stream. 
Upon leaving the dryer, the HG is sent to a two-stage dedusting system, comprising of a cyclone dedusting unit (first stage) and a bag dedusting unit (second stage), to remove the DS particulate. The dedusted $\mathrm{HG}$, at $180{ }^{\circ} \mathrm{C}$, is sent to a cooling and washing tower. In the cooling and washing tower, reclaimed water and sodium hydroxide $(\mathrm{NaOH})$ solution, at $20^{\circ} \mathrm{C}$, are fed from the top, and the $\mathrm{HG}$ enters the tower from the bottom. The countercurrent cooling and washing process condenses the moisture and removes most of the $\mathrm{SO}_{2}$ from the $\mathrm{HG}$ stream. Upon the completion of cooling and washing, the $\mathrm{HG}$ at $60{ }^{\circ} \mathrm{C}$ is further sent to a regenerative thermal oxidation (RTO) furnace and the washing medium at $40{ }^{\circ} \mathrm{C}$ is sent back to the WWTP. Air and natural gas (NG) at $20^{\circ} \mathrm{C}$ are fed to the RTO furnace to allow for the NG combustion, which supplies thermal energy to initiate and maintain the deodorization process of the entering HG stream. The deodorized HG stream, at $90{ }^{\circ} \mathrm{C}$, is vent to the atmosphere through a chimney.

The DS particulate removed by the dedusting system is merged with the DS stream from the dryer, and the combined DS stream is naturally cooled to $30{ }^{\circ} \mathrm{C}$ and sent to a DS storage unit for temporary storage. The pyrolysis process of the DS is accomplished by a set of three furnaces, including a pre-heating furnace, a tube-shell structured pyrolysis furnace, and a re-combustion furnace. To initiate the pyrolysis process, air and $\mathrm{NG}$ at $20{ }^{\circ} \mathrm{C}$ are fed to the pre-heating furnace for $\mathrm{NG}$ combustion, which creates a $\mathrm{HG}$ stream at $600^{\circ} \mathrm{C}$. This $\mathrm{HG}$ stream is sent into the shell of the pyrolysis furnace to raise the tube temperature to a desired pyrolysis temperature, e.g., $450{ }^{\circ} \mathrm{C}$. When the tube temperature reaches its set value, DS is fed into the tube for pyrolysis, and the heat exchange between the HG stream and the DS stream follows the crossflow manner in general. During the pyrolysis, moisture and volatile organic compounds (VOCs), released by the DS, enter the shell of the pyrolysis furnace through the pores on the tube wall. These VOCs are combusted in the shell of the pyrolysis furnace, and the HG stream is further heated to $840{ }^{\circ} \mathrm{C}$. This HG stream is further heated to $850{ }^{\circ} \mathrm{C}$ by NG combustion in the re-combustion furnace and sent to the hot air furnace. NG combustion in the hot air furnace will not increase the temperature but the flowrate of the 
HG stream, and the final HG stream enters the dryer to close the heat-integration loop. The pyrolyzed sludge, PS, leaving the pyrolysis furnace at $450{ }^{\circ} \mathrm{C}$, is sent to a water-jacketed heat exchanger for cooling and moisturization. Reclaimed water at $20{ }^{\circ} \mathrm{C}$ is taken from the WWTP as the cooling medium, flowed concurrently with the PS stream, and returned to the WWTP at $40{ }^{\circ} \mathrm{C}$. The PS stream is moisturized with $5-10 \%$ (weight percent) tap water in the heat exchanger, cooled down to $50{ }^{\circ} \mathrm{C}$, and sent to a PS storage.

In the above full-scale sludge pyrolysis process, certain considerations and implications, e.g., DS moisture content and air supply, are naturally integrated into the system design. These considerations and implications, often overlooked, have profound effects on the environmental and economic performance of the pyrolysis system. Hence, they will be introduced and discussed here.

First, in many studies regarding the pyrolysis of sludge and/or biomass, the dry sludge/biomass leaving the dryer is assumed to be absolutely dry, i.e., moisture content $<10 \%$. This assumption has negligible impacts on the system energy balance, yet it is inapplicable in the full-scale design as it could introduce significant safety hazards to the system. The safety hazards are linked to the combustion of VOCs. When the DS moisture content is too low and the DS temperature is sufficiently high, i.e., $110{ }^{\circ} \mathrm{C}$, the combustion of VOCs might occur at the exit of the dryer, and combustion of VOCs will further result in the combustion of the DS. Hence, in the full-scale sludge pyrolysis process, the DS still contains $20 \%$ moisture, and this value could be further increased to $30 \%$ if the FS organic content is high (and thus the VOCs content is high).

Next, air plays a critical role in the sludge pyrolysis process. Even though pyrolysis is an anaerobic thermal process, it still requires a working fluid, and hot air (hot gas HG) is responsible for most of the heat and mass transfer in the pyrolysis process. Air at ambient temperature is introduced into the system by two manners, either actively by fans or passively by the pressure difference at equipment inlet/outlet. 
The total amount of air involved in the sludge pyrolysis process is determined by a subtle mass-energy balance (MEB). On the one hand, total amount of air should satisfy the requirement for NG combustion, VOCs combustion, and HG generation. On the other hand, the energy released by NG and VOCs combustion must be sufficient to generate enough $\mathrm{HG}$ at desired temperature. In general, if air was not properly accounted for, both the system NG consumption and the system electricity requirement would be underestimated. Such underestimations eventually lead to less accurate estimation of the environmental and economic performance for the pyrolysis system. As such, the role of air will be properly accounted for in this work to improve the accuracy of LCA and TEA calculations.

Furthermore, heat loss of the sludge pyrolysis system is usually neglected in the previous studies. In the sludge pyrolysis process, all furnaces are operating at high temperature, e.g., $850{ }^{\circ} \mathrm{C}$, so heat loss from the system to the environmental is inevitable, even if an optimal insulation layer is built around each piece of equipment. Neglecting such heat loss has two direct outcomes. If the heat loss is neglected, the NG consumption for heat compensation is also ignored, so the system NG consumption is underestimated. Also, the heat loss is often system size-dependent, i.e., a small pyrolysis system usually has higher unit heat loss than a large pyrolysis unit, so ignoring the heat loss will likely lead to an incorrect conclusion that the system energy consumption is independent from the system size. Hence, system heat loss data will be provided in this work to further improve the accuracy of LCA and TEA calculations.

Finally, heat substitution is often implemented in the previous studies, to deliver a more optimistic forecast on the environmental and economic performance of the pyrolysis system. However, heat substitution is currently less applicable in the full-scale design due to two challenges. The major challenge is the heat integration in the system. In the full-scale design, NG is always consumed by the pre-heating furnace, the re-combustion furnace and the RTO furnace. Consequently, the hot air furnace is the only furnace that could be shut down during the steady-state operation to export high-quality thermal energy, 
i.e., $\mathrm{HG}$ at $850{ }^{\circ} \mathrm{C}$, if the amount of $\mathrm{HG}$ leaving the re-combustion furnace exceeds the amount of $\mathrm{HG}$ required by the dryer. Unfortunately, the heat output pipeline is not installed on the hot air furnace in the current design, and the excess thermal energy, i.e., excess amount of HG, will be removed from the system by flowing more reclaimed water through the cooling and washing tower. The other challenge is based on practical considerations. The sludge pyrolysis system is located in a WWTP, and it is less likely to find another process within a reasonable range that has high demand for thermal energy. In this work, the sludge pyrolysis system with and without heat substitution will both be evaluated, to improve the comprehensiveness of the LCA and TEA analysis.

\subsection{Calculation Inputs and Parameter Space}

Estimating the environmental and economic performance of the pyrolysis system requires the knowledge on the system material consumptions, e.g., NG consumption and reclaimed water consumption. These system material consumptions are obtained by performing MEB calculations on the full-scale municipal sludge pyrolysis system described in Section 2.1. Performing the MEB calculations requires several inputs (at minimum), e.g., sludge properties and system design information, and they will be introduced and discussed in the following section. All the MEB calculations involved in this work were kindly conducted by Wuhan Pro-Envi Tech Co., Ltd (China), using their full-scale sludge pyrolysis process design program.

\subsubsection{Sludge Organic Content and Elemental Composition}

Sludge organic content has profound influences on the system environmental and economic performance [27]. First, sludge organic content affects the NG consumption of the pyrolysis system. As mentioned earlier, heat is supplied to the pyrolysis system in two ways, the NG combustion and the VOCs combustion. Meanwhile, the total amount of heat required by the pyrolysis system is almost a constant if 
the sludge organic content is the only variable. Consequently, if more energy is provided by the VOCs combustion, then less energy is required from the NG combustion so the system NG consumption becomes lower. Generally, an increase in the energy provided by VOCs combustion is observed when more VOCs are available, which further relates back to an increase in the sludge organic content. Hence, if the sludge to be pyrolyzed has higher organic content, the NG consumption of the pyrolysis system decreases. Next, sludge organic content also affects the $\mathrm{NaOH}$ consumption of the pyrolysis system. If the sludge to be pyrolyzed has higher organic content, this sludge will likely contain more Sulfur, thus more $\mathrm{NaOH}$ will be consumed in the cooling and washing tower, when the desulfurization efficiency is fixed. In this work, nine sludge organic content values, ranging from $30 \%$ to $70 \%$ with an interval of $5 \%$, were used for the MEB calculations, to study the effects of sludge organic content on the system environmental and economic performance. The chosen sludge organic content range, i.e., $30 \%$ to $70 \%$, is representative of the municipal sludge conditions in China, i.e., sludge with an organic content below $30 \%$ or above $70 \%$ is rarely encountered in China.

Similar to the sludge organic content, the sludge elemental composition also affects the system environmental and economic performance, and these effects are more prominent when the sludge organic content is fixed. For example, a sludge with higher $\mathrm{C}$ content may have higher heating value than another sludge with higher $\mathrm{O}$ content, when the organic content of the two sludges is identical. If both sludges are pyrolyzed, the system that pyrolyzes the former sludge may have lower NG consumption. Hence, variations in the system environmental and economic performance, arising from the fluctuations in sludge elemental composition, must also be taken into consideration for each organic content analyzed. In this work, we generated ten hypothetical DS-PS pairs with different elemental composition at each organic content. The elemental composition of these ninety hypothetical DS-PS pairs is generally consistent with 
both the data collected by us over the past ten years and the data reported by other studies. Detailed information regarding the properties of the ninety hypothetical DS-PS pairs could be found in Table S1.

\subsubsection{Sludge Moisture Content}

Sludge moisture content has enormous impacts on the system environmental and economic performance. Conventionally, the FS taken from a WWTP contains $80 \%$ moisture, so the mass of moisture to be removed is four times that of the DS. Evaporating such amount of moisture is highly energy intensive, i.e., consumes a large amount of NG, because water has high heat capacity and latent heat of evaporation. Hence, if FS containing less than $80 \%$ moisture is fed to the pyrolysis system, the NG consumption of the pyrolysis decreases. For example, when the FS moisture content is reduced to $70 \%$, the mass of moisture is only 2.33 times that of the DS, and the heat required to remove moisture is reduced by $41.7 \%$. In this work, seven sludge moisture content values, namely $70 \%, 75 \%$ to $80 \%$ with $1 \%$ interval, were used for the MEB calculations, to elucidate the role of sludge moisture content in determining the system environmental and economic performance. The lowest moisture content was chosen to be $70 \%$, because this value represents the dehydration limit of high-pressure belt dehydrators. Further dehydration generally requires the addition of polymeric amorphous ferric chloride (PAFC) and or quicklime $(\mathrm{CaO})$, and both compounds would make the sludge less suitable for pyrolysis. Therefore, further dehydration below $70 \%$ is not considered in this work.

\subsubsection{System Size and Energy Distribution}

In addition to the sludge properties discussed in Section 2.2.1 and 2.2.2, system design information, e.g., system size and energy distribution, is also important in determining the system environmental and economic performance. 
The system size, i.e., how much FS ( $80 \%$ moisture) the system could handle per day, affects the system NG consumption. As mentioned earlier, the larger the system, the lower the unit heat loss, i.e., heat loss per ton DS. Consequently, less NG (per ton DS) is required to compensate the heat loss when the system size increases. In this work, three system sizes, $20 \mathrm{t}$ FS/d, $50 \mathrm{t}$ FS/d and $100 \mathrm{t}$ FS/d, were used in the MEB calculations, to reveal the influences of the system on the system environmental and economic performance. The average heat loss values for the three system sizes are $1020 \mathrm{MJ} / \mathrm{t} \mathrm{FS,} 578 \mathrm{MJ} / \mathrm{t}$ FS and $418 \mathrm{MJ} / \mathrm{t} \mathrm{FS}$, respectively. When a $20 \mathrm{t}$ FS /d pyrolysis system is replaced by a $100 \mathrm{t}$ FS /d pyrolysis, the system heat loss is reduced by almost $60 \%$.

Finally, the system energy distribution, i.e., the temperature of HG entering the re-combustion furnace, also influences the system NG consumption. In the system described in Section 2.1, the HG enters the recombustion furnace at $840{ }^{\circ} \mathrm{C}$, and is further heated to $850{ }^{\circ} \mathrm{C}$. If the $\mathrm{HG}$ enters the re-combustion furnace at lower temperature, e.g., $750{ }^{\circ} \mathrm{C}$, more air at room temperature needs to be fed to the pyrolysis furnace as a diluent, and the HG flowrate increases accordingly. Consequently, more HG enters the re-combustion furnace at lower temperature, so more NG will be consumed in the re-combustion furnace to raise the HG temperature to $850^{\circ} \mathrm{C}$. Furthermore, as more $\mathrm{HG}$ at $850{ }^{\circ} \mathrm{C}$ is produced by the re-combustion furnace, less NG is required by the hot air furnace. Overall, the heat duty is shifted from the hot air furnace to the recombustion furnace, and such energy re-distribution might change the system NG consumption. For example, if the hot air furnace is already shut down when the HG enters the re-combustion furnace at $840^{\circ} \mathrm{C}$, further lowering the $\mathrm{HG}$ temperature will lead to an increase in the system NG consumption, when no heat substitution is implemented. In this work, three temperatures, $750{ }^{\circ} \mathrm{C}, 800{ }^{\circ} \mathrm{C}$ and $840^{\circ} \mathrm{C}$, were used in the MEB calculations, to explore the impacts of system energy distribution on the system environmental and economic performance. 
The inputs and parameter space discussed in Section 2.2.1 through 2.2.3 are summarized in Table. 1. In basic MEB calculations, only sludge organic content and sludge elemental composition were varied, and other parameters were fixed as $80 \%$ (sludge moisture content), $100 \mathrm{t} \mathrm{FS/d}$ (system size) and $840{ }^{\circ} \mathrm{C}$ (system energy distribution). In advanced MEB calculations, sludge organic content, sludge elemental composition and one other parameter, e.g., sludge moisture content, were varied, and the rest of the parameters were fixed at their base value, e.g., $100 \mathrm{t}$ FS/d for system size. The outputs from MEB calculations, e.g., system material consumptions, were intermediate values in this study, since they were further used as inputs for LCA and TEA calculations. Given the large amount of data involved in this work, we only presented the system NG consumption, among all the outputs from MEB calculations, in the Results and Discussion Section.

Table. 1 Inputs and parameter space for the MEB calculations. The base values are bolded.

\section{Entry Name}

Dry Sludge Organic Content (wt\%)

Dry Sludge Elemental Composition (wt\%)

Pyrolyzed Sludge Elemental Composition (wt\%)

Feed Sludge Moisture Content (wt\%)*

Sludge Pyrolysis System Size (t FS/d)

System Heat Loss (MJ/t FS)

\section{Input Values}

$30,35,40,45,50,55,60,65,70$

Summarized in Table. S1

Summarized in Table. S1

$70,75,76,77,78,79, \mathbf{8 0}$

$20,50,100$

1020 (20 t FS/d), 578 (50 t FS/d),

418 (100 t FS/d) 


\begin{abstract}
System Energy Distribution (Temperature at the Entrance of the $750,800,840$
Re-combustion Furnace, ${ }^{\circ} \mathrm{C}$ )

De-sulfurization Efficiency (\%) $\quad 90$ (with $10 \% \mathrm{NaOH}$ in excess)

* For FS with moisture content lower than $80 \%$, the total amount of FS the system handles decreases such that the amount of DS fed to the pyrolysis furnace remains the same. For example, a system that handles 100 t FS with $80 \%$ moisture (corresponding to 20 t DS) only handles 66.67 t FS with $70 \%$ moisture (corresponding to $20 \mathrm{t} \mathrm{DS}$ ).
\end{abstract}

\title{
2.3 Life Cycle Assessment
}

The MEB calculations described in Section 2.2 reveal the key materials and energy consumption features of the full-scale sludge pyrolysis system, and the calculation results were used to estimate the environmental impacts of the pyrolysis system via life cycle assessment (LCA). LCA is an environmental accounting tool that determines the environmental impacts of products, processes, and/or systems, from cradle to grave $[23,28]$. The goal of LCA in this work is to first investigate the environmental performances of the full-scale pyrolysis system under a wide range of conditions, i.e., the parameter space described in Section 2.2, and then provide insights on the system optimizations that would make pyrolysis a more sustainable and promising solution for sludge handling in the future. Prior to conducting LCA, the functional unit (FU) must be properly designated. In previous studies on the thermal treatment of sludge, two types of FU, the wet mass-based FU and the dry weight-based FU, were often used interchangeably. However, in this study, the feed sludge moisture content was systematically varied, so the wet mass of feed sludge was no longer a constant. As such, selecting the FU based on the dry weight is more appropriate, and we chose the FU as handling 1 metric ton sludge on a dry weight basis. In the rest of this 
study, the material and energy consumptions, the system environmental impacts, and the system economic performances will be reported based on this FU.

LCA was conducted in the Excel spreadsheet using Ecoinvent v3.6 database, and it converted four major inputs into seven metrics [29]. The three major inputs are system natural gas consumption, system $\mathrm{NaOH}$ consumption, system water consumption and system electricity consumption. The first three inputs are obtained from MEB calculations (Section 2.2) and their values depended on the sludge properties and/or the system properties, while the system electricity consumption are independent of those properties. For the system presented in this work, the installed electricity consumption capacity is $642 \mathrm{kWh} / \mathrm{t} \mathrm{DS}$ and the operating electricity consumption capacity is $40 \%$ to $50 \%$ of this value, i.e., 256.8 to $321.0 \mathrm{kWh} / \mathrm{t} \mathrm{DS}$. The seven metrics are global warming potential (GWP100, $\mathrm{kg} \mathrm{CO}_{2}$-Eq), freshwater eutrophication (FEP, kg P-Eq), human toxicity (HTP100, kg 1,4-DCB-Eq), particulate matter formation (PMFP, kg PM10-Eq), terrestrial acidification (TAP100, $\mathrm{kg} \mathrm{SO}_{2}$-Eq), water depletion (WDP, $\mathrm{m}^{3}$ ) and cumulative energy demand (CED, MJ-Eq). These seven metrics, varying from climate change to air and water pollution to human health, are generally sufficient to provide a comprehensive estimation of environmental impacts associated with waste handling processes. The conversion of four inputs to six non-GWP metrics was done by simply adding up the product of energy/material consumptions and their corresponding life cycle environmental burdens. In the net GWP calculations, the greenhouse gas emissions were first calculated using the same manner, and the carbon sequestration credits from biochar were then subtracted from the greenhouse gas emissions. The carbon sequestration credits from biochar were calculated by multiplying the yield of biochar (t PyS/t DS), the carbon content of biochar (\%), the carbon to $\mathrm{CO}_{2}$ equivalent ratio $(12 \mathrm{~kg} \mathrm{C}-44$ $\left.\mathrm{kg} \mathrm{CO}_{2}\right)$ and the carbon stability of biochar $(0.7$ for biochar obtained from the sludge pyrolysis conditions [30]). The four inputs and discussed above are summarized in Table. 2.

Table. 2 Inputs and input-to-metric conversion factors for LCA calculations. 


\section{Entry Name}

System NG Consumption (kg/t DS)*

System $\mathrm{NaOH}$ Consumption (kg/t DS)

System Water Consumption $\left(\mathrm{m}^{3} / \mathrm{t} \mathrm{DS}\right)$

System Electricity Consumption (kWh/t DS) 256.8 to 321.0

\section{Input Values}

Obtained from MEB, presented in Figure 4

Summarized in Table. S1

Obtained from MEB

* The heating value of NG used in this work is $50.919 \mathrm{MJ} / \mathrm{kg}$ (HHV).

\subsection{Techno-economic Assessment}

The economic performances of the pyrolysis system were estimated via techno-economic assessment (TEA). The total cost of sludge handling using the pyrolysis system could be classified into the capital cost and the operating cost. The capital cost is comprised of the cost for equipment purchase and installation and the cost for engineering and construction, and this cost only depends on the system size. For the sludge pyrolysis system presented in this work, the total capital investment (one-time investment) is 15 million CNY, 35 million CNY or 65 million CNY, when the system size is $20 \mathrm{t} / \mathrm{d}, 50 \mathrm{t} / \mathrm{d}$ and $100 \mathrm{t} / \mathrm{d}$, respectively. In addition to the one-time investment, $1 \%$ of the total capital investment is required annually for the system maintenance, e.g., 0.65 million $\mathrm{CNY}$ is required annually for the maintenance of a $100 \mathrm{t} / \mathrm{d}$ sludge pyrolysis system. The operating cost is comprised of the material and energy cost and the labor cost, and this cost depends on both the sludge properties and the system design. The material and energy cost covers both the utilization of water, $\mathrm{NG}$, electricity, and $\mathrm{NaOH}$ and the transportation of pyrolyzed sludge. As mentioned earlier, the pyrolysis system is built within a WWTP, so the utilization of water is free of charge. As for $\mathrm{NG}$, electricity and $\mathrm{NaOH}$, their unit prices are $3.28 \mathrm{CNY} / \mathrm{m}^{3}, 0.661 \mathrm{CNY} / \mathrm{kWh}$, and $2500 \mathrm{CNY} / \mathrm{t}$, respectively. The transportation of pyrolyzed sludge adds an additional $40 \mathrm{CNY} / \mathrm{t}$ 
(pyrolyzed sludge) to the material and energy cost. It should be noted that when thermal energy could be exported from the system, e.g., when the sludge organic content is high enough and heat substitution is applied, the exported thermal energy is converted to an equivalent amount of NG and sold at $3.28 \mathrm{CNY} / \mathrm{m}^{3}$. The labor cost covers the basic salary and social insurance of the engineers who run and manage the sludge pyrolysis system. For each set of sludge pyrolysis system, twelve engineers are needed, regardless of the system size, and the annual salary and social insurance for each of them is $60000 \mathrm{CNY}$.

The components of the total cost were then used to generate two major economic indices, the minimum sludge handling price (MSHP) (of handling $1 \mathrm{t} \mathrm{DS}$ ) and the ratio of variable operating and maintenance cost (VOM) to MSHP. The first economic index, MSHP, is defined as the lowest handling price at which the sludge needs to be charged in order to maintain a designated internal rate of return (IRR) while accounting for the capital cost, the operating cost, and the market value of any byproducts, e.g., exported thermal energy in this study. The calculation of MSHP followed the classic discounted cash flow rate of return method, and this calculation involved several assumptions. First, we assumed the plant lifetime to be 30 years, and the plant was built using 30\%/70\% equity/debt financing and a 16-year loan with $5 \%$ debt rate. Next, an IRR of $6 \%$ and an income tax of $25 \%$ were used. Further, a seven-year Modified Accelerated Cost Recovery System (MACRS) schedule was applied to all pieces of equipment. Finally, the pyrolysis plant was assumed to be operating for 336 days annually, i.e., 29/30 days required for maintenance. Under these assumptions, the MSHP was retrieved as the price that made the net present value (NPV) of the project zero at the end of the plant lifetime. The second economic index, the ratio of variable operating and maintenance cost (VOM) to MSHP, measures the sensitivity of the MSHP to the operating conditions, i.e., MSHP is more sensitive to the operating conditions when this ratio increases. The VOM was calculated using the non-labor operating cost and the system maintenance cost. All the costs and the economic assumptions discussed in this section are summarized in Table. 3. 
Table. 3 Summary of costs and economic assumptions

Entry Name $\quad$ Input Values

Total Capital Investment (CNY) 15 million (20 t FS/d), 35 million (50 t FS/d), 65 million (100 t $\mathrm{FS} / \mathrm{d})$

Annual Maintenance Fee (CNY) $\quad 0.15$ million (20 t FS/d), 0.35 million (50 t FS/d), 0.65 million $(100 \mathrm{t} \mathrm{FS/d})$

$\mathrm{NG}\left(\mathrm{CNY} / \mathrm{m}^{3}\right)$

Electricity $(\mathrm{CNY} / \mathrm{kWh}) \quad 0.661$

$\mathrm{NaOH}(\mathrm{CNY} / \mathrm{t}) \quad 2500$

Pyrolyzed Sludge Transportation 40

$(\mathrm{CNY} / \mathrm{t})$

Annual Salary and Social Insurance 60000 per person, 0.72 million totals (12 engineers)

(CNY)

Plant lifetime (year) 30 


\begin{tabular}{ll}
\hline Construction Financing & $30 \% / 70 \%$ equity/debt, 16-year loan with 5\% debt rate \\
IRR and Tax Rate $(\%)$ & $6 \%$ and $25 \%$ \\
Annual Operating Time (days) & 336
\end{tabular}

\section{Results and Discussions}

\subsection{Natural Gas Consumption of the Pyrolysis System}

Among all the outputs from MEB calculations, the system NG consumption is the most important one in determining the system environmental and economic performance, and is thus presented in Figure 2. As shown in Figure 2 (A) through (D), the system NG consumption is affected by several factors to different extents, and these factors generally fall in two categories, the feed sludge properties and the system design parameters. In the following discussions, the effects of feed sludge properties on the system NG consumption will be examined first, followed by the investigation on the influences of system design parameters. 

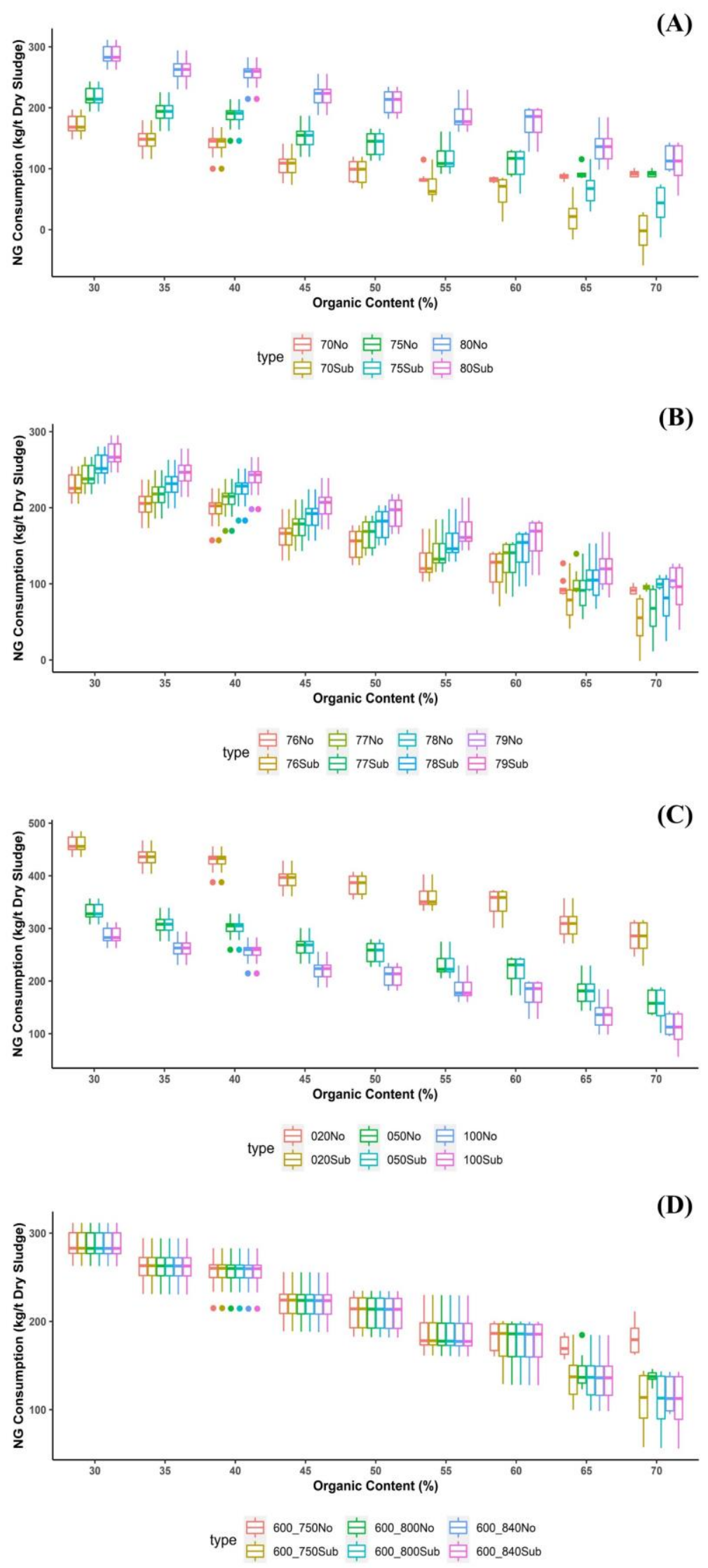
Figure 2. Natural gas consumption of the pyrolysis system as a function of (A, B) sludge organic content and feed sludge moisture content, (C) sludge organic content and pyrolysis system size and (D) sludge organic content and system energy distribution. In the legends, the words "No" and "Sub" correspond to the situations where heat substitution is not considered and is considered, respectively.

In the basic scenario, i.e., FS contains $80 \%$ moisture, the system handles $100 \mathrm{t} \mathrm{FS/d}$ and the entrance temperature of re-combustion furnace is $840^{\circ} \mathrm{C}$, the system NG consumption decreases monotonically with increasing sludge organic content, regardless of the choice on the system heat substitution. When the sludge organic content increases from $30 \%$ to $70 \%$, the average system NG consumption decreases from 287.2 $\mathrm{kg} / \mathrm{t}$ DS and $287.2 \mathrm{~kg} / \mathrm{t}$ DS (with heat substitution) to $117.4 \mathrm{~kg} / \mathrm{t}$ DS and $109.9 \mathrm{~kg} / \mathrm{t}$ DS (with heat substitution). Meanwhile, systems without heat substitution have identical NG consumption as systems with heat substitution if the sludge organic content is below $65 \%$, and the latter systems have slightly lower NG consumption only if the sludge organic content is $70 \%$. These two observations could be explained from the heat supply and heat integration manners of the system. First, if the sludge moisture content is fixed, the heat required (per mass of dry sludge) to evaporate moisture is almost a constant, and the total amount of heat is supplied by both the NG combustion and the VOCs combustion. For sludge with higher organic content, more VOCs are generally available, so more heat is supplied by VOCs combustion in the pyrolysis furnace and less heat is required from the NG combustion in the hot air furnace. Therefore, the system NG consumption decreases with increasing sludge organic content. Next, if the sludge organic content is so high that heat generated by VOCs combustion is sufficient, i.e., the flowrate of HG leaving the re-combustion furnace meets/exceeds the drying demand, the hot air furnace would no longer consume NG or consume a negative amount of NG (with heat substitution). Hence, the observation, that heat substitution only makes a marginal difference on the system NG consumption, suggests the heat 
produced from VOCs combustion is insufficient to evaporate the moisture, even when the sludge organic content is as high as $70 \%$.

Compared to the basic scenario, a reduction in the sludge moisture content leads to lower system NG consumption at equivalent sludge organic content (Figure $2(\mathrm{~A})$ ). For example, if the feed sludge contains $75 \%$ moisture (instead of $80 \%$ moisture), the average system NG consumption varies from $218.5 \mathrm{~kg} / \mathrm{t}$ DS and $218.5 \mathrm{~kg} / \mathrm{t}$ DS (with heat substitution) to $91.9 \mathrm{~kg} / \mathrm{t} \mathrm{DS}$ and $41.2 \mathrm{~kg} / \mathrm{t}$ DS (with heat substitution), when the sludge organic content increases from $30 \%$ to $70 \%$. When the feed sludge is further dewatered to $70 \%$, i.e., the dehydration limit of high-pressure belt dehydrators, the system NG consumption is ultimately reduced to $172.7 \mathrm{~kg} / \mathrm{t}$ DS and $172.7 \mathrm{~kg} / \mathrm{t}$ DS (with heat substitution) at 30\% sludge organic content and $91.9 \mathrm{~kg} / \mathrm{t}$ DS and $-4.6 \mathrm{~kg} / \mathrm{t}$ DS (with heat substitution) at 70\% sludge organic content. Overall, dewatering the feed sludge from $80 \%$ to $70 \%$ could lower the system NG consumption by up to $104.2 \%$ ( $70 \%$ sludge organic content, with heat substitution), and this observation could be explained from the system heat supply manner as well. When the feed sludge moisture content is reduced at equivalent sludge organic content, less water (per mass of dry sludge) is evaporated, so less heat is required from the VOCs combustion and the NG combustion. Meanwhile, the total amount of DS fed to the pyrolysis furnace is fixed, so the total amount of heat supplied by the VOCs combustion is fixed. Hence, less heat is required from the NG combustion, and the system NG consumption decreases correspondingly.

In the basic scenario, heat substitution only makes a marginal difference in the system NG consumption, and the system NG consumption decreases monotonically with increasing sludge organic content. Different trends are observed when the feed sludge moisture content is $75 \%$ or $70 \%$. For these two sludge moisture contents, systems with heat substitution still have NG consumption that decreases monotonically with increasing sludge organic content. However, for systems without heat substitution, their NG consumption first decreases with increasing sludge organic content till a global minimum value, 
and then slightly increases with further increase in the sludge organic content. When the feed sludge moisture content is $70 \%$, the minimum NG consumption is $82.5 \mathrm{~kg} / \mathrm{t} \mathrm{DS}$ at $60 \%$ sludge organic content. When the feed sludge moisture content is $75 \%$, the minimum NG consumption is $91.6 \mathrm{~kg} / \mathrm{t} \mathrm{DS}$ at $65 \%$ sludge organic content. These observations, i.e., the system NG consumption reaches a minimum value at lower sludge organic content and then increases slightly, are explained as follows. As mentioned earlier, the amount of VOCs available for combustion is positively correlated with the sludge organic content, and the hot air furnace would no longer consume NG if the heat generated by VOCs combustion is sufficient. In the basic scenario, such conditions are only met when the sludge organic content is as high as $70 \%$. However, when the feed sludge moisture content is reduced to $75 \%$ or $70 \%$, less heat is required to evaporate water. Consequently, the amount of VOCs from sludge with lower organic content becomes sufficient to provide the heat for water evaporation, so the hot air furnace could be shut down during the steady-state operation and the system NG consumption reaches its minimum value at lower sludge organic content. When the minimum system NG consumption is achieved, any further increase in the sludge organic content leads to VOCs in excess. The combustion of the excess amount of VOCs would require an excess amount of air, and air is preheated by the NG combustion to meet the temperature requirement for the combustion of VOCs. Therefore, the system NG consumption increases slightly with further increase in the sludge organic content. If the presence of air is neglected, then the system NG consumption would remain constant once its minimum value is reached, i.e., the system NG consumption would be $82.5 \mathrm{~kg} / \mathrm{t}$ DS instead of $91.9 \mathrm{~kg} / \mathrm{t}$ DS when the feed sludge organic content and the feed sludge moisture content are both $70 \%$. We do not recommend neglecting the presence of air, as such approximation/assumption fails to capture two of the key features of the pyrolysis system, i.e., air is consumed in combustion and air is the major working fluid of the system. 
It has been confirmed that systems without heat substitution no longer have NG consumption that decreases monotonically with increasing sludge organic content, when the feed sludge moisture content is $75 \%$. Hence, a critical sludge moisture content, i.e., the moisture content below which monotonic decreasing trend does not occur, should exist. To find this critical point, four more sludge moisture contents, falling between $75 \%$ and $80 \%$, were included in the MEB calculations, and the corresponding results are presented in Figure 2 (B). For feed sludge with $79 \%$ or $78 \%$ moisture content, the trend observed is identical to that observed for the basic scenario. For feed sludge with $78 \%$ or $77 \%$ moisture content, heat substitution starts to make a difference in the system NG consumption when the sludge organic content is $65 \%$, while the monotonic decreasing trend preserves. Therefore, it is concluded that the critical sludge moisture content is $76 \%$.

The analysis and discussions above highlight the effects of feed sludge organic and feed sludge moisture content on the system NG consumption. In addition to these sludge properties, the system design parameters, e.g., system size and system energy distribution, also have profound influences on the system NG consumption. Compared to the basic scenario, a reduction in the system size could lead to significantly higher system NG consumption at equivalent sludge organic content (Figure 2 (C)). For example, if a 100$\mathrm{t}$ pyrolysis system is replaced by two 50-t pyrolysis systems, the average system NG consumption would increase to $332.2 \mathrm{~kg} / \mathrm{t}$ DS and $332.2 \mathrm{~kg} / \mathrm{t}$ DS (with heat substitution) at $30 \%$ sludge organic content and $160.5 \mathrm{~kg} / \mathrm{t}$ DS and $154.9 \mathrm{~kg} / \mathrm{t}$ DS (with heat substitution) at $70 \%$ sludge organic content. If the system size further reduces to 20 -t, the average system NG consumption eventually reaches $460.3 \mathrm{~kg} / \mathrm{t} \mathrm{DS}$ and 460.3 $\mathrm{kg} / \mathrm{t}$ DS (with heat substitution) at $30 \%$ sludge organic content and $284.8 \mathrm{~kg} / \mathrm{t} \mathrm{DS}$ and $283.0 \mathrm{~kg} / \mathrm{t} \mathrm{DS}$ (with heat substitution) at $70 \%$ sludge organic content. Overall, the system NG consumption would increase by $158 \%$ (70\% sludge organic content, with heat substitution) when the system size is reduced to 20 -t, and this observation is a direct outcome of system heat loss. As mentioned earlier, pyrolysis systems with 
smaller scale usually have higher unit heat loss, i.e., heat loss per mass FS or DS. For the three sizes of system considered here, their heat loss values are $5100 \mathrm{MJ} / \mathrm{t}$ DS (20-t), $2890 \mathrm{MJ} / \mathrm{t}$ DS (50-t) and $2090 \mathrm{MJ} / \mathrm{t}$ DS (100-t), respectively. Such heat loss is compensated by combusting more NG, so the system NG consumption increases significantly. Meanwhile, combusting more NG would require more air to be preheated, which also leads to a minor increase in the system NG consumption. It should be noted that the increase in system NG consumption, when a large-scale pyrolysis system is replaced by a small-scale one, is not simply the heat loss divided by the NG heating value, as the MEB of the whole system is reconfigured when the heat loss changes. For the pyrolysis system presented in this work, the system NG consumption would increase by $1 \mathrm{~kg} / \mathrm{t}$ DS when the system heat loss increases by 17-19 MJ/t DS.

Compared to other factors discussed previously, the system energy distribution is the least significant factor that affects the system NG consumption. For systems with heat substitution, tuning system energy distribution does not create any influences on the system NG consumption. For systems without heat substitution, the effects of system energy distribution are non-trivial only when the sludge organic content is above $65 \%$. For example, the system NG consumption at $70 \%$ sludge organic content would increase from $117.4 \mathrm{~kg} / \mathrm{t}$ DS to $137 \mathrm{~kg} / \mathrm{t}$ DS or $180.9 \mathrm{~kg} / \mathrm{t} \mathrm{DS}$, when the entrance temperature of the re-combustion furnace decrease from $840{ }^{\circ} \mathrm{C}$ to $800{ }^{\circ} \mathrm{C}$ or $750{ }^{\circ} \mathrm{C}$. These results could be explained from the system heat integration manners. First, the flowrate of HG entering the re-combustion furnace/leaving the pyrolysis furnace increases with increasing sludge organic content. As sludge organic content increases, more VOCs are combusted in the pyrolysis furnace, and more air is supplied to the pyrolysis furnace for the VOCs combustion. Both factors result in an increase in the HG flowrate. Next, to lower the temperature of HG entering the re-combustion furnace, e.g., from $840{ }^{\circ} \mathrm{C}$ to $750{ }^{\circ} \mathrm{C}$, air needs to be supplied as a thermal diluent, and the amount of air required is positively-correlated to the HG flowrate. Hence, as sludge organic content increases, more air is required to dilute the HG stream. Furthermore, as more HG at lower 
temperature enters the re-combustion furnace, more NG will be consumed in this furnace to bring the HG temperature to $850^{\circ} \mathrm{C}$. Finally, as more $\mathrm{HG}$ at $850{ }^{\circ} \mathrm{C}$ is readily generated by the re-combustion furnace, less HG needs to be generated by the hot air furnace and less NG will be consumed in the hot air furnace. In the basic scenario, i.e., $\mathrm{HG}$ enters the re-combustion furnace at $840{ }^{\circ} \mathrm{C}$, the $\mathrm{HG}$ flowrate is almost sufficient to cover the drying requirement, when the sludge organic content is above $65 \%$. Under these conditions, diluting the HG streams would lead to a situation where the re-combustion furnace generates an excess amount of $\mathrm{HG}$, so the system NG consumption increases.

The key features of the system NG consumption are summarized below. For systems with heat substitution, increasing the sludge organic content or reducing the feed sludge moisture content leads to lower system NG consumption, while configuring the system energy distribution has no effects on the system NG consumption. For systems without heat substitution, reducing the feed sludge moisture content still leads to lower system NG consumption, while the effects of sludge organic content depend on the sludge moisture content. When the feed sludge moisture content is above $76 \%$, increasing the sludge organic content leads to lower system NG consumption. When the feed sludge moisture content is below $76 \%$, a minimum system NG consumption is achieved at lower sludge organic content. Nevertheless, configuring a higher entrance temperature for the re-combustion furnace in the system energy distribution could reduce the system NG consumption for systems without heat substitution. For both types of systems, conducting sludge pyrolysis at larger scale always leads to lower system NG consumption.

\subsection{Environmental Impacts of the Pyrolysis System}

\subsubsection{System Global Warming Potential}

The system GWP is an indicator of its $\mathrm{CO}_{2}$ emissions. If the system has a positive GWP value, $\mathrm{CO}_{2}$ is discharged into the atmosphere. If the system has a negative GWP value, $\mathrm{CO}_{2}$ is sequestrated by the 
system. Under the global warming mitigation frameworks, waste handling systems with low (but still positive) or negative GWP values are always preferrable, as these systems create minimum environmental burdens or even environmental benefits in the waste treatment. The GWP associated with the full-scale sludge pyrolysis system is presented in Figure 3, and the system GWP is affected by both the feed sludge properties and the system design parameters. 

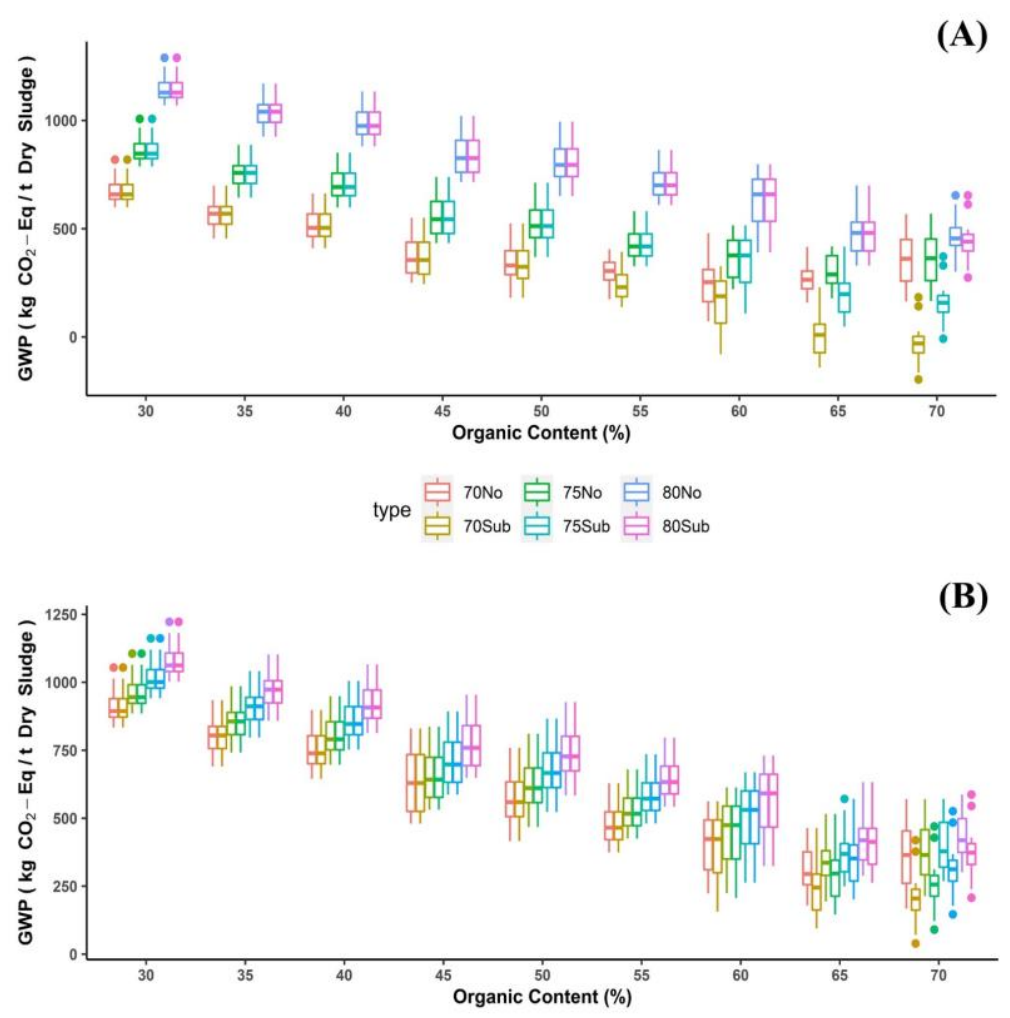

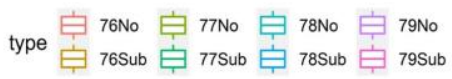
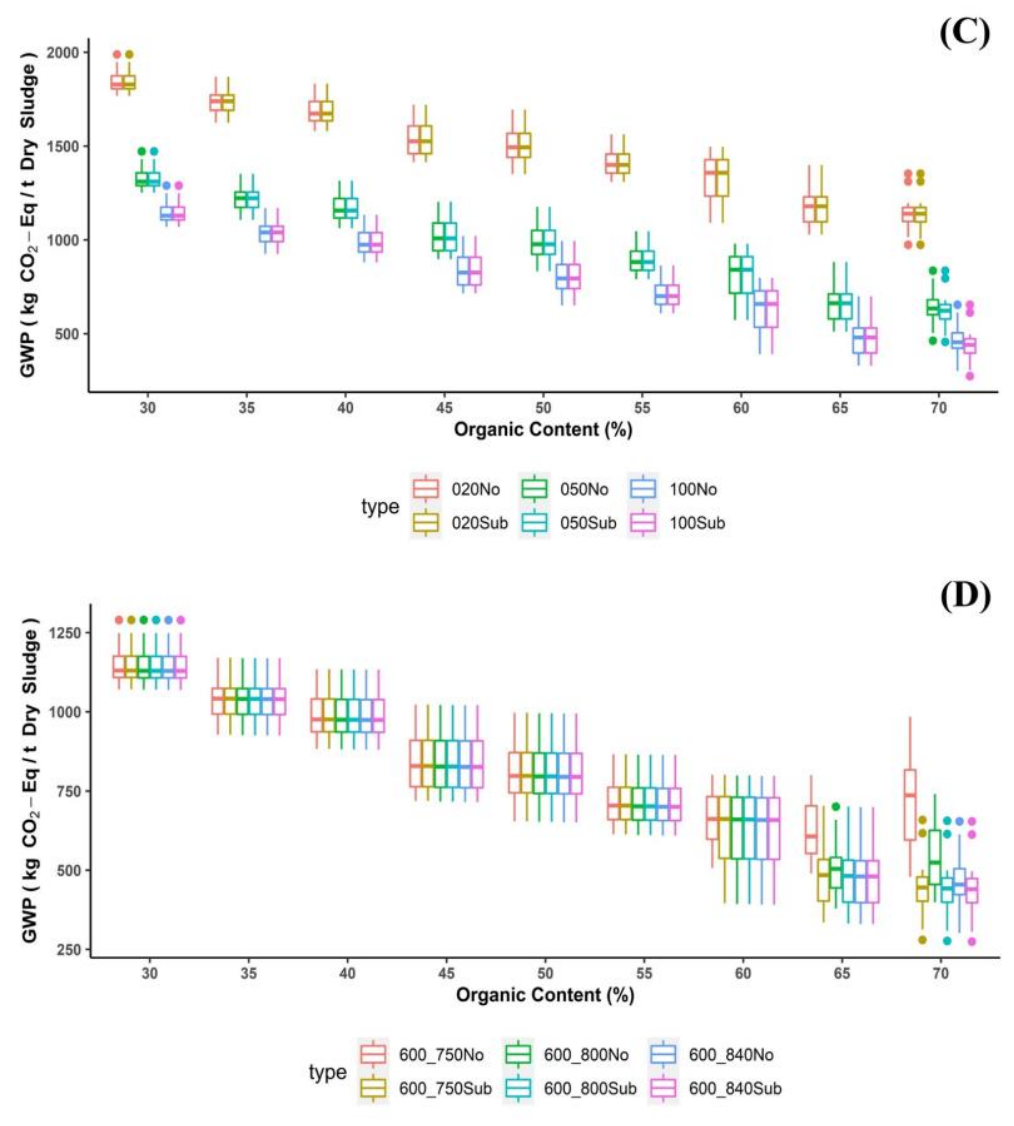
Figure 3. System GWP as a function of (A, B) sludge organic content and feed sludge moisture content, (C) sludge organic content and pyrolysis system size and (D) sludge organic content and system energy distribution.

Generally, the trends of system GWP (Figure 3) resembles the trends of system NG consumption (Figure 2). This observation is explained as follows. First, the contribution of system energy consumptions to its GWP is much greater compared to that of system material consumptions. Furthermore, the system electricity consumption (per FU) is a constant, so the change in the GWP associated with system energy consumptions is solely determined by the system NG consumption. In the basic scenario (" 80 " series in Figure 3(A)), the system GWP decreases with increasing sludge organic content. When the sludge organic content increases from $30 \%$ to $70 \%$, the average system GWP decreases from $1147.0 \mathrm{~kg} \mathrm{CO}$-Eq/t DS and $1147.0 \mathrm{~kg} \mathrm{CO} 2-\mathrm{Eq} / \mathrm{t} \mathrm{DS}$ (with heat substitution) to $468.4 \mathrm{~kg} \mathrm{CO}_{2}-\mathrm{Eq} / \mathrm{t} \mathrm{DS}$ and $438.1 \mathrm{~kg} \mathrm{CO}-\mathrm{Eq} / \mathrm{t} \mathrm{DS}$ (with heat substitution). The reduction in the system GWP suggests that pyrolysis is more environmentally attractive in handling sludge with relatively high organic content. Compared to the basic scenario, a reduction in the feed sludge moisture content leads to lower system GWP at equivalent sludge organic content ("70" and "75" series in Figure 4(A)). When the feed sludge moisture content is reduced to $75 \%$, the average system GWP varies from $864.6 \mathrm{~kg} \mathrm{CO}$-Eq/t DS and $864.6 \mathrm{~kg} \mathrm{CO}$-Eq/t DS (with heat substitution) at $30 \%$ sludge organic content to $361.6 \mathrm{~kg} \mathrm{CO}-\mathrm{Eq} / \mathrm{t} \mathrm{DS}$ and $155.8 \mathrm{~kg} \mathrm{CO}$-Eq/t DS (with heat substitution) at $70 \%$ sludge organic content. If the feed sludge is further dewatered to $70 \%$ moisture content, the average system GWP decreases from $674.6 \mathrm{~kg} \mathrm{CO}_{2}-\mathrm{Eq} / \mathrm{t} \mathrm{DS}$ and $674.6 \mathrm{~kg} \mathrm{CO} 2-\mathrm{Eq} / \mathrm{t} \mathrm{DS}$ (with heat substitution) to $359.4 \mathrm{~kg} \mathrm{CO}-\mathrm{Eq} / \mathrm{t} \mathrm{DS}$ and $-32.5 \mathrm{~kg} \mathrm{CO}-\mathrm{Eq} / \mathrm{t} \mathrm{DS}$ (with heat substitution), when the feed sludge organic content increases from $30 \%$ to $70 \%$. The negative GWP, though only achieved for one set of conditions, suggests that pyrolysis could handle a hazardous waste, i.e., sludge, and create environmental benefits, i.e., $\mathrm{CO}_{2}$ sequestration, simultaneously. Overall, reducing the feed sludge 
moisture content from $80 \%$ to $70 \%$ could lead to a system GWP reduction by up to $107.4 \%$ (70\% sludge organic content, with heat substitution). Similar to the system NG consumptions, the system GWP exhibits a local minimum value when the feed sludge is dewatered and heat substitution is not applied. For example, when the feed sludge contains $75 \%$ or $70 \%$ moisture, the minimum system GWP is $299.1 \mathrm{~kg} \mathrm{CO}_{2}-\mathrm{Eq} / \mathrm{t}$ DS at $65 \%$ sludge organic content or $250.0 \mathrm{~kg} \mathrm{CO}_{2}$-Eq/t DS at $60 \%$ sludge organic content. By examining four additional sludge moisture content, i.e., 76\%, 77\%, 78\% and 79\%, it could be concluded system GWP no longer decreases monotonically with increasing sludge organic content, i.e., the system GWP exhibits a local minimum value, as soon as the feed sludge is dewatered from $80 \%$ to $79 \%$ (Figure 4(B)). Compared to the system NG consumption, the critical sludge moisture content increases from $76 \%$ to $80 \%$, and this shift is likely caused by the contribution of other material consumptions to the system GWP.

In addition to the sludge properties discussed above, the system design parameters also affect the system GWP. First, an increase in the system size could significantly reduce the system GWP at equivalent sludge organic content (Figure 3(C)). When the system size is 20-t, its GWP varies from $1846.0 \mathrm{~kg} \mathrm{CO}_{2}$ $\mathrm{Eq} / \mathrm{t} \mathrm{DS}$ and $1846.0 \mathrm{~kg} \mathrm{CO}$-Eq/t DS (with heat substitution) at $30 \%$ sludge organic content to $1144.3 \mathrm{~kg}$ $\mathrm{CO}_{2}-\mathrm{Eq} / \mathrm{t} \mathrm{DS}$ and $1137.1 \mathrm{~kg} \mathrm{CO} 2-\mathrm{Eq} / \mathrm{t} \mathrm{DS}$ (with heat substitution) at $70 \%$ sludge organic content. If the system size is increased to 50 - $\mathrm{t}$, these values reduce to $1328.9 \mathrm{~kg} \mathrm{CO}$-Eq/t DS and $1328.9 \mathrm{~kg} \mathrm{CO}$-Eq/t DS (with heat substitution) at $30 \%$ sludge organic content to $642.4 \mathrm{~kg} \mathrm{CO}$-Eq/t DS and $620.1 \mathrm{~kg} \mathrm{CO}_{2-}$ Eq/t DS (with heat substitution) at 70\% sludge organic content. If the system size further increased to 100t, i.e., the basic scenario, the system GWP is further lowered to its base values. Overall, the system GWP could be reduced by up to $61.5 \%$ (70\% sludge organic content, with heat substitution) if five sets of 20 -t pyrolysis system are replaced by one set of 100-t pyrolysis system. This conclusion highlights the significant environmental merits of centralized sludge treatment. Finally, the system energy distribution has minor effects on the system GWP. Similar to the system NG consumption, these effects only exist 
when heat substitution is not applied and the sludge organic content is above $65 \%$. For example, the system GWP at $70 \%$ sludge organic content would decrease from $726.3 \mathrm{~kg} \mathrm{CO} 2-\mathrm{Eq} / \mathrm{t} \mathrm{DS}$ to $548.3 \mathrm{~kg} \mathrm{CO}$-Eq/t DS or $468.4 \mathrm{~kg} \mathrm{CO} 2-\mathrm{Eq} / \mathrm{t} \mathrm{DS}$, when the entrance temperature of the re-combustion furnace is elevated from $750{ }^{\circ} \mathrm{C}$ to $800{ }^{\circ} \mathrm{C}$ or $840{ }^{\circ} \mathrm{C}$. Hence, using a higher entrance temperature for the re-combustion furnace is recommended, when the material of construction permits.

The analysis and discussions on system GWP reveal the possible pathways that could be taken in the future to minimize the carbon footprint in pyrolysis-based sludge handling. Among the rest six LCA metrics, CED is often used interchangeably with GWP, i.e., systems with high GWP have high CED, FEP, HTP, PMFP and TAP do not vary significantly with the sludge properties and the system design parameters (compared to GWP and CED). As such, the results for these five metrics are presented in the Supporting Information. The system WDP, however, exhibits different trends compared to the previous six metrics. Hence, the system WDP will be presented and discussed in the following section.

\subsubsection{System Water Depletion}

The system WDP is an indicator of its tendency in amplifying water scarcity. The higher the system WDP, the more likely the system would amplify water scarcity. For the sludge pyrolysis system in this work, its WDP is almost independent of sludge organic content or the system energy distribution but largely dependent on the sludge moisture content and system size. This observation is explained as follows. In the pyrolysis system, the majority of water is consumed in the cooling and washing tower for cooling purpose. As mentioned earlier, the dedusted $\mathrm{HG}$ entered the tower at $180{ }^{\circ} \mathrm{C}$ and a certain relative humidity (R.H) and left the tower at $60{ }^{\circ} \mathrm{C}$ and $100 \%$ R.H. During the cooling process, the air in the HG was cooled down, the moisture in the HG was cooled down, and the condensation of moisture occurred. Given the high latent heat of condensation of water, the amount of water condensed is the major factor that 
determines the water consumption of the cooling tower (or the WDP of the system). Hence, if the flowrate of $180^{\circ} \mathrm{C}$ HG decreases (same R.H), the system WDP decreases (Figure 4 (A, B)). Similarly, if the R.H of the $180^{\circ} \mathrm{C} \mathrm{HG}$ decreases, the system WDP decreases as well (Figure $4(\mathrm{C})$ ). It is worth noting that decreasing the feed sludge moisture content from $80 \%$ to $70 \%$ only removes $1.67 \mathrm{t}$ water/t DS, yet doing so could reduce the system WDP by almost $50 \mathrm{~m}^{3} / \mathrm{t}$ DS. Therefore, dewatering the feed sludge in the sludge pyrolysis not only leads to less $\mathrm{CO}_{2}$ emission (Section 3.2.1) but also saves water. These environmental benefits could be more prominent in areas suffering from water scarcity, as water production in those areas might have higher carbon footprints. 

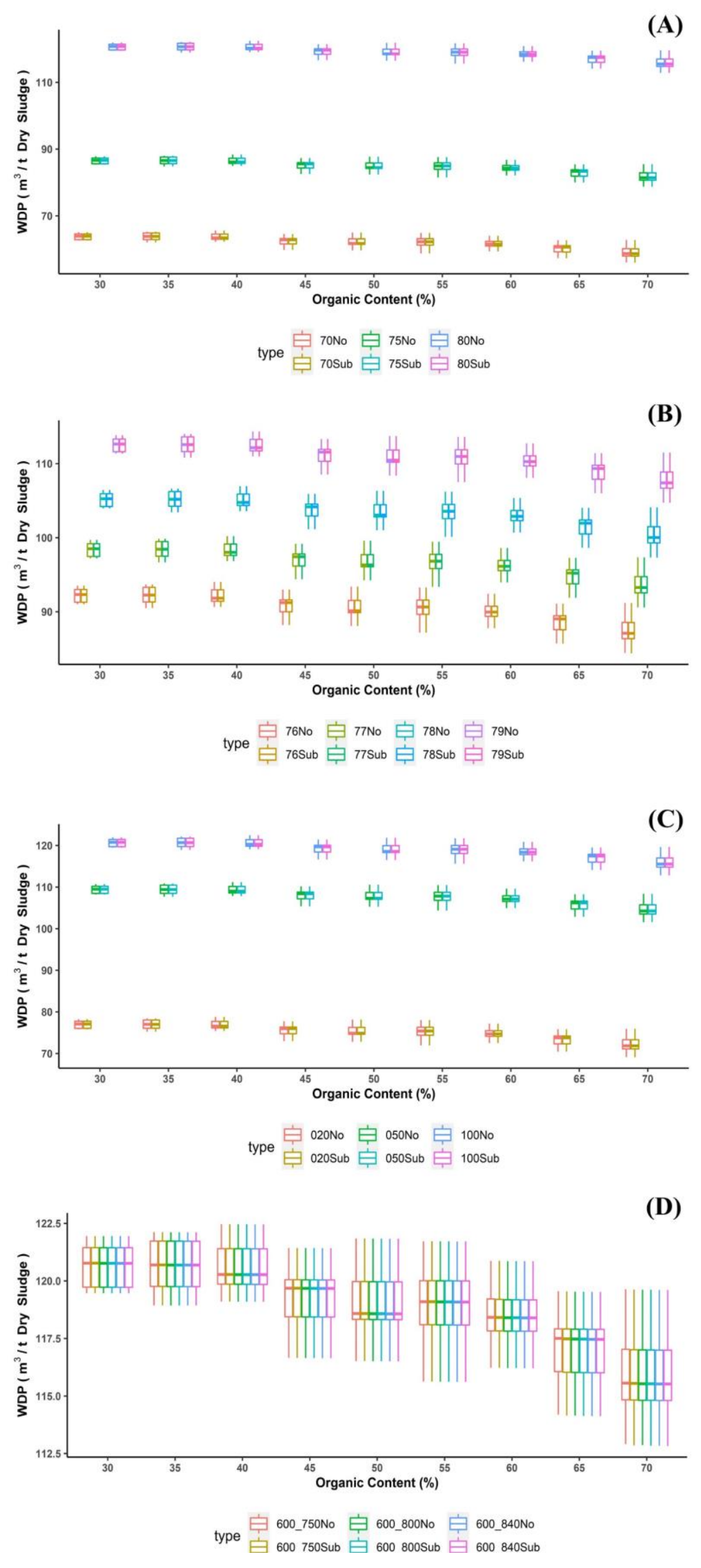
Figure 4. System WDP as a function of (A, B) sludge organic content and feed sludge moisture content,

(C) sludge organic content and pyrolysis system size and (D) sludge organic content and system energy distribution.

\subsection{Economic Performance of the Pyrolysis System}

\subsubsection{Minimum Sludge Handling Price}

The MSHP is the metric that estimates the economic performance of a sludge handling system. When a sludge handling system has a positive MSHP, this system creates net economic burdens for the society. When a sludge handling system has a negative MSHP, this system delivers net economic benefits to the society. Therefore, a reduction in the system MSHP corresponds to an improvement in the system economic performance, and systems with lower MSHP are more preferrable in sludge handling. The MSHP of the full-scale sludge pyrolysis system under various of conditions are shown in Figure 5. 

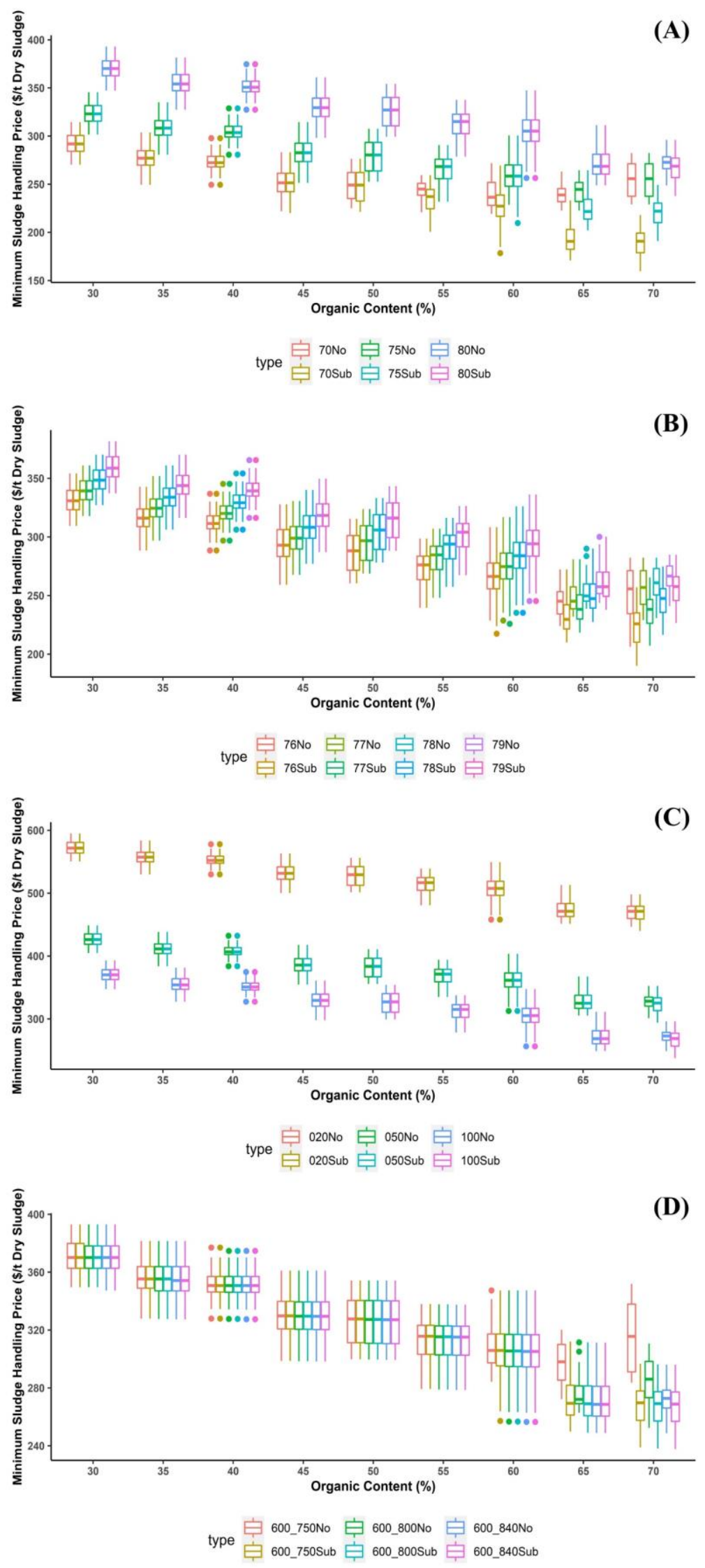
Figure 5. Minimum sludge handling price as a function of $(A, B)$ sludge organic content and feed sludge moisture content, (C) sludge organic content and pyrolysis system size and (D) sludge organic content and system energy distribution.

The trends observed for the system MSHP are mostly consistent with the trends observed for the system GWP (Figure 3), as the operating cost part of the system MSHP is made up of the factors that also determine the system GWP, e.g., NG consumption and electricity consumption. In the basic scenario, i.e., the "80" series in Figure 5(A), an increase in the sludge organic content leads to a reduction in the system MSHP. When the sludge organic content increases from 30\% to 70\%, the average system MSHP decreases from 369.9 \$/t DS and 369.9 \$/t DS (with heat substitution) to 271.9 \$/t DS and 266.8 \$/t DS (with heat substitution). Similar to the conclusion from system GWP, i.e., pyrolysis becomes more environmentally attractive in handling sludge with high organic content, the observed trend in system MSHP suggests that pyrolysis is also more economic preferable in handling such sludge. However, the system MSHP is much less sensitive to the change in sludge organic content than the system GWP. This result is not surprising. The change in sludge organic content only affects the variable operating and maintenance cost part of the system MSHP, and this part only accounts for 50 - $65 \%$ of the total MSHP, i.e., the rest 35 - $50 \%$ of the total MSHP is made up of the capital costs and labor costs that are independent of sludge properties and/or operating conditions. Compared to the basic scenario, dewatering the feed sludge generally leads to lower system MSHP at equivalent sludge organic content, as shown by the "75" and "70" series in Figure 5(A). If a feed sludge with $75 \%$ moisture content is handled with the pyrolysis system, the average system MSHP decreases from 323.2 \$/t DS and 323.2 \$/t DS (with heat substitution) to 254.5 \$/t DS and 220.0 \$/t DS (with heat substitution), when the feed sludge organic content increases from $30 \%$ to $70 \%$. When the feed sludge moisture content is further reduced to 70\%, the system MSHP varies from 292.0 \$/t DS and 292.0 \$/t DS (with heat substitution) at 30\% sludge organic content to 254.5 \$/t DS and 188.8 \$/t DS 
(with heat substitution) at $70 \%$ sludge organic content. Unlike the case with system GWP, where negative GWP or net environmental benefits could be achieved by the pyrolysis system under one set of conditions, the system MSHP always has a positive value, which suggests the pyrolysis system always create net economic burdens for the society. However, it is still possible to further reduce the system MSHP, and potential pathways of doing so will be discussed in the Perspective Section. In general, dewatering the feed sludge could reduce the system MSHP by up to $29.2 \%$ (70\% sludge organic content, with heat substitution). Similar to the system GWP, the system MSHP would have a local minimum value at $65 \%$ sludge organic content, when the feed sludge is dewatered and heat substitution is not applied (Figure 5 (A) and (B)), and the rationale behind this observation has been extensively discussed in Section 3.1 and 3.2.1.

The discussions above focused on the effects of sludge properties on the system MSHP. Aside from these factors, the system size and system energy distribution also influence the system MSHP, and their effects are sometimes more prominent. First, a negative correlation between the system size and the system MSHP is observed (Figure 5(C)). For example, a 20-t system would have MSHP values ranging from 572.2 \$/t DS and 572.2 \$/t DS (with heat substitution) at 30\% sludge organic content to $470.1 \$ / \mathrm{t}$ DS and 468.9 \$/t DS (with heat substitution) at $70 \%$ sludge organic content. When a 50-t system is used, these values would reduce to 426.4 \$/t DS, 426.4 \$/t DS, 326.9 \$/t DS and 323.1 \$/t DS, respectively. Overall, a maximum $43 \%$ saving in the system MSHP could be achieved (70\% sludge organic content, with heat substitution) if one set of 100-t pyrolysis system is used to replace 5 sets of 20 -t pyrolysis system. This conclusion further reveals the economic preferability of centralized sludge handling (in addition to the environmental merits discussed in Section 3.2.1). It is also worth noting that the effects of system size on the system MSHP is more prominent than that of sludge properties, as system size not only affects the variable operating and maintenance cost, e.g., the cost for NG consumption, but also influence the capital 
investments, e.g., the unit price of a 100-t system is lower than that of a 20 -t system. Finally, the system energy distribution only leads to less than $15 \%$ difference in the system MSHP, and the effects of system energy distribution is non-trivial only when heat substitution is not applied and the sludge organic content is above 65\%. Similar to the discussions in Section 3.1 and 3.2.1, increasing the higher entrance temperature for the re-combustion furnace also promotes the economic performance of the pyrolysis system.

The above analysis offers a valuable bridge that connects the system economic performance to the sludge properties and system design parameters. However, a deeper understanding on the structure of MSHP, i.e., the weights of VOM in MSHP, is required, to better improve the system economic performance in the future. Hence, the ratio of VOM to MSHP will be presented and discussed in the following section.

\subsubsection{Contribution of VOM to MSHP}



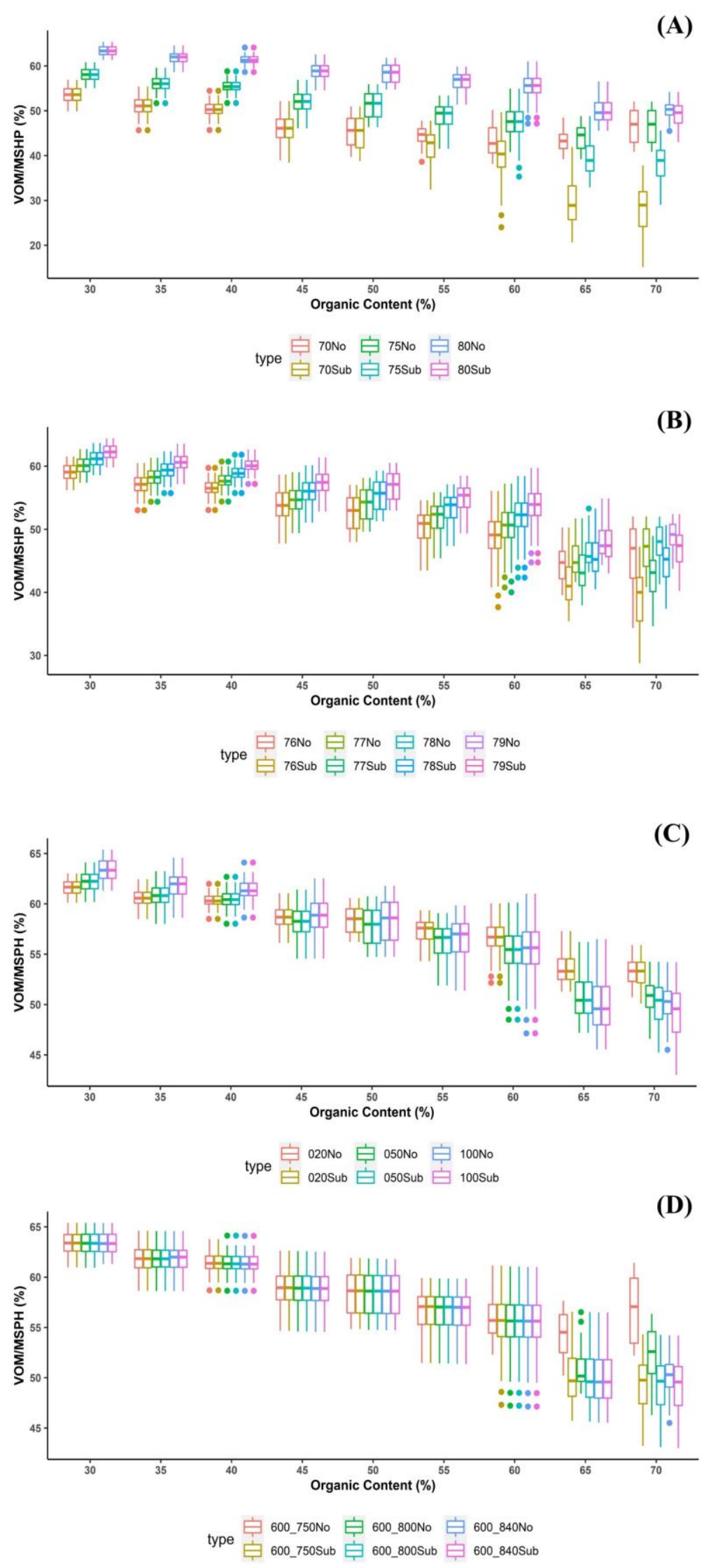
Figure 6. The ratio between VOM and MSHP as a function of (A, B) sludge organic content and feed sludge moisture content, (C) sludge organic content and pyrolysis system size and (D) sludge organic content and system energy distribution.

The contribution of VOM to the MSHP, under various conditions, is shown in Figure 6. As mentioned earlier, the system VOM is made up of energy consumptions, material consumptions and the transportation of pyrolyzed sludge. In general, the VOM to MSHP ratio falls between $30 \%$ to $65 \%$, and the specific values depend on both the sludge properties and the system design parameters. Consistent with the previous results, e.g., system GWP and MSHP, sludge organic content significantly influences the VOM to MSHP ratio. In the basic scenario, the VOM to MSHP ratio decreases from $63 \%$ to $57 \%$, when the organic content of sludge increases from $30 \%$ to $70 \%$. This $6 \%$ decrease in the VOM to MSHP ratio is mainly attributed to the reduced system NG consumption, which leads to a net decrease in the total VOM. Additionally, whether or not heat substitution is applied only affects the ratio between VOM and MSHP when the feed sludge is dewatered and the sludge organic content is high. For example, if a feed sludge with $70 \%$ organic content is dewatered to $70 \%$ moisture content, the average VOM to MSHP ratio is $\sim 30 \%$ with heat substation or $\sim 50 \%$ without heat substitution. Such remarkable difference is explained by the potential economic benefits of using the waste heat from the pyrolysis system as an alternative to NG, yet the applicability of doing so is still controversial. Compared to the sludge properties, the system size appears to have less significant impacts on the VOM/MSHP. When the system size decreases, both the capital investments and the operating costs increase. The magnitudes of the increase are similar, such that the overall VOM/MSHP remains relative unchanged. Finally, similar to previous results, the system energy distribution has marginal impacts on VOM/MSHP.

The results from VOM/MSHP analysis provides further insights on optimizing the economic performance of the sludge pyrolysis system at full scale. The VOM and capital investments are equally 
important in determining the system economic performance, so both of them should be considered in the optimizations. Further discussions on this topic will be provided in the Perspective Section.

\section{Perspectives}

\subsection{Pretreatment of the Feed Sludge}

In the Results and Discussions Section, we have extensively discussed the profound influences of sludge properties on the environmental and economic performance of the pyrolysis system. From those analysis, two pathways, i.e., dewatering the feed sludge and promoting the sludge organic content, could help the pyrolysis system achieve better environmental and economic performance, and both pathways could be taken immediately or in the near future. It should be noted that sludge dewatering and sludge inorganic-organic matter separations are both associated with certain environmental and economic burdens, so they should only be taken when the burdens are lower than the benefits, as the ultimate goal is promoting the environmental and economic performance of the pyrolysis system rather than creating new issues. In the following discussions, we will evaluate the feasibility of dewatering and provide metrics on when sludge inorganic-organic matter separations shall be considered.

The benefits of sludge dewatering depend on whether heat substitution is applied. For system with heat substitution, dewatering the sludge from $80 \%$ to $70 \%$ moisture content would decrease the system GWP and MSHP by $\sim 470 \mathrm{~kg} \mathrm{CO}$-Eq/t DS and $\sim 78$ \$t DS, respectively. For system without heat substitution, the minimum environmental and economic benefits of dewatering the sludge, occurring at $70 \%$ sludge organic content, are $\sim 109 \mathrm{~kg} \mathrm{CO}$-Eq/t DS and $\sim 17$ \$t DS, respectively. Hence, the minimum allowed environmental/economic burdens of dewatering are $109 \mathrm{~kg} \mathrm{CO}$-Eq/t DS / 17 \$/t DS. We conducted a series of dewatering tests at pilot scale, i.e., $72-96$ t $80 \%$ moisture content FS/d, using highpressure belt dehydrators, and the cost and $\mathrm{CO}_{2}$ emissions are 5.1 - 6.7 \$t DS (including capital cost, 
calculated using the same method as MSHP) and $13.8-18.3 \mathrm{~kg} \mathrm{CO}$-Eq/t DS $(21.25-28.33 \mathrm{kWh}$ electricity /t DS). These values are much lower than the minimum allowed burdens of dewatering, so dewatering the feed sludge to $70 \%$ is always recommended for the pyrolysis system, regardless of the situation of heat substitution.

Similar to the dewatering, heat substitution also determines the benefits of sludge inorganic-organic matter separations. When heat substitution is applied, a 5\% increase in the sludge organic content would decrease the system GWP and MSHP by $\sim 85 \mathrm{~kg} \mathrm{CO} 2$-Eq/t DS and $\sim 13$ \$/t DS, respectively. If heat substitution is not applied, a critical point, i.e., the point below which the system GWP and MSHP decrease monotonically, exist for dewatered sludge. Under such conditions, the environmental and economic benefits listed above, i.e., $~ 85 \mathrm{~kg} \mathrm{CO}$-Eq/t DS and $\sim 13 \$ / \mathrm{DS}$, only persist if the sludge organic content is $10 \%$ below the critical point, e.g., below $50 \%$ organic content when the feed sludge moisture content is $70 \%$ (critical point at $60 \%$ organic content). Compared to the dewatering, sludge inorganic-organic matter separations are much less frequently conducted or reported, possibly due to the technical challenges. If the sludge inorganic-organic matter separations were to be carried out in the future, the values listed above could be used to estimate the environmental and economic feasibility of such separations.

\subsection{Finding Add-on Value for the Pyrolyzed Sludge}

The environmental and economic performance of the pyrolysis system may also be improved if the pyrolyzed sludge could be used as an alternative to other products, e.g., adsorbents [14, 31, 32], fertilizer [33-35] and soil amendment [36-38]. Using pyrolyzed sludge as adsorbent is perhaps its most commonly studied application. The pyrolyzed sludge could undergo chemical/thermal activations, and the activated pyrolyzed sludge could be used as an alternative to the commercially available activated carbon [14, 39]. However, the carbon content of pyrolyzed sludge is often not high enough [15], and this drawback 
eventually limits the specific surface area and pore volume of the obtained activated pyrolyzed sludge. Consequently, a (much) larger amount of activated pyrolyzed sludge is required to achieve the same adsorption performance, e.g., pollutant removal efficiency, as commercial activated carbon, and producing such amount of activated pyrolyzed sludge is associated with further emissions and costs. We only recommend activating the pyrolyzed sludge when its carbon content is sufficiently high. When pyrolyzed sludge is applied as a fertilizer or a soil amendment, not further physical/chemical treatment is required. We conducted a series of agricultural experiments, using Chinese cabbage, cucumber and eggplant, to study the performance of pyrolyzed sludge as a fertilizer and a soil amendment. In our experiments, the pyrolyzed sludge itself could not promote the vegetable yield to the same extent as traditional fertilizer did, even when the dosage of pyrolyzed sludge is an order of magnitude higher than that of the fertilizer. However, when the pyrolyzed sludge is used together with the fertilizer, the soil acidification (caused by the use of fertilizer) is alleviated. Hence, applying the pyrolyzed sludge as a soil amendment might be more promising than applying it as a fertilizer. Further research efforts are required to quantify the environmental and economic benefits of using pyrolyzed sludge as a soil amendment and characterize the possible long-term migration of heavy metals from the pyrolyzed sludge into the soil or agricultural products.

\subsection{Long-term Goals}

In the long-term optimization of the sludge pyrolysis system, the following three pathways shall be taken into consideration. First, decarbonized electricity and zero-carbon fuels should be used. In the current system, the consumption of fuel (NG) and electricity contributes significantly to the system GWP, either directly, i.e., as themselves, or indirectly, i.e., in the production of chemicals. Therefore, the system GWP would reduce significantly if the fuel and electricity are largely decarbonized. In the ideal case, i.e., the fuel and electricity are 100\% decarbonized, the GWP of pyrolysis system could become negative, as 
the emissions from fuel and electricity are eliminated while the $\mathrm{CO}_{2}$ sequestration effects from pyrolyzed sludge persist [16]. Next, sewage and stormwater should be collected and treated separately [40, 41]. Currently, the sewage and stormwater are collected together in many parts of China, and the combined stream is sent to the WWTPs [11]. The stormwater generally has better overall quality compared to the sewage, i.e., the COD/BOD/SS of stormwater is lower, so treating stormwater together with sewage would waste energy. Meanwhile, the large volume of stormwater also leads to a reduction in the sludge organic content. Hence, separate collection of stormwater and sewage would push the water and sludge treatment towards a more sustainable end. Finally, further advances in the equipment manufacturing are required. If the capital investments of the pyrolysis system reduce significantly, e.g., by $30 \%-50 \%$, a $20 \%$ saving in the system MSHP is totally achievable.

\section{Conclusions}

In this paper, process based LCA and TEA were conducted to study the environmental and economic performance of sludge pyrolysis systems at varying conditions, including different feed moisture content, sludge organic content, system size of the plant, and system energy distribution. Our results quantified the significant impacts of natural gas consumption on the environmental and economic performance of the sludge pyrolysis system. Generally, feed sludge with lower moisture content and higher sludge organic content leads to lower natural gas consumption, which can be further translated into lower GWP and MSHP, and vice versa. The system size of the plant also affects the environmental and economic performance. A larger sludge pyrolysis system has lower GWP and MSHP, which indicates the environmental and economic merits of centralized sludge handling. Finally, the system energy distribution has negligible impacts on both environmental and economic performance. In the most ideal case, the average GWP and MSHP of sludge pyrolysis could be as low as $-32.5 \mathrm{~kg} \mathrm{CO} 2$-Eq/t DS and $188.8 \$ / \mathrm{DS}$, respectively. Based on our LCA and TEA results, we discussed the pathways, e.g., pretreating the sludge 
and finding add-on values of the pyrolyzed sludge, that could be taken to further optimize the environmental and economic performances of the pyrolysis system.

To the best of our knowledge, this work is the first comprehensive LCA and TEA study that investigates the environmental and economic performance of full-scale sludge pyrolysis systems in China. The findings of this article not only help guide the design and optimization of the sludge pyrolysis plant but also provide valuable insights into other full-scale pyrolysis processes, e.g., biomass pyrolysis. The data from this study is also beneficial to inform decision-makers to incorporate pyrolysis as an environmentally-friendly and cost-effective option for sludge management.

\section{CRediT Authorship Contribution Statement}

Hongxi Luo: Conceptualization, Methodology, Investigation, Validation, Visualization, Analysis, Writing original draft, Writing - review \& editing. Fangwei Cheng: Conceptualization, Methodology, Visualization, Analysis, Writing - original draft, Writing - review \& editing. Bin Yu: Investigation, Validation. Lei Hu: Investigation, Validation. Junfa Zhang: Investigation, Validation. Xiangpeng Qu: Investigation, Validation. Hai Yang: Investigation, Validation. Zhen Luo: Conceptualization, Investigation, Validation, Writing - review \& editing.

\section{Declaration of Competing Interest}

The authors declare that they have no known competing financial interests or personal relationships that could have appeared to influence the work reported in this paper.

\section{Acknowledgments}

We thank the engineers at Wuhan Pro-Envi Tech Co., Ltd for their kind suggestions on the mass and energy balance calculations. Specific inquiries on the MEB calculations should be sent to Dr. Zhen Luo (luozhen@proenvitech.com), who is the GM of Wuhan Pro-Envi Tech Co., Ltd. 


\section{Reference:}

1. M. Buaisha, S. Balku, and S. Özalp-Yaman, Heavy metal removal investigation in conventional activated sludge systems. Civil Engineering Journal, 2020. 6(3): p. 470-477.

2. A. Lizasoain, L.F.L. Tort, M. García, L. Gillman, A. Alberti, J.P.G. Leite, M.P. Miagostovich, S.A. Pou, A. Cagiao, and A. Razsap, Human enteric viruses in a wastewater treatment plant: evaluation of activated sludge combined with UV disinfection process reveals different removal performances for viruses with different features. Letters in applied microbiology, 2018. 66(3): p. 215-221.

3. S. Babel and D. del Mundo Dacera, Heavy metal removal from contaminated sludge for land application: a review. Waste Management, 2006. 26(9): p. 988-1004.

4. Q.H. Zhang, W.N. Yang, H.H. Ngo, W.S. Guo, P.K. Jin, M. Dzakpasu, S.J. Yang, Q. Wang, X.C. Wang, and D. Ao, Current status of urban wastewater treatment plants in China. Environment international, 2016. 92: p. 11-22.

5. K. Fijalkowski, A. Rorat, A. Grobelak, and M.J. Kacprzak, The presence of contaminations in sewage sludge-The current situation. Journal of Environmental Management, 2017. 203: p. 1126-1136.

6. L. Wei, F. Zhu, Q. Li, C. Xue, X. Xia, H. Yu, Q. Zhao, J. Jiang, and S. Bai, Development, current state and future trends of sludge management in China: Based on exploratory data and $\mathrm{CO}_{2}$-equivaient emissions analysis. Environment International, 2020. 144: p. 106093.

7. H. Chen, S.H. Yan, Z.L. Ye, H.J. Meng, and Y.G. Zhu, Utilization of urban sewage sludge: Chinese perspectives. Environmental Science and Pollution Research, 2012. 19(5): p. 1454-1463.

8. G. Yang, G. Zhang, and H. Wang, Current state of sludge production, management, treatment and disposal in China. Water research, 2015. 78: p. 60-73.

9. L. André, A. Pauss, and T. Ribeiro, Solid anaerobic digestion: State-of-art, scientific and technological hurdles. Bioresource technology, 2018. 247: p. 1027-1037.

10. J.T. Luan Dong, Zhou Yang, Jennifer L. Turner and Coco Liu, Scaling Sludge Mountains Breaking Down Barriers for Chinese Cities to Turn Sludge Waste into Energy 2018. 
11. L. Feng, J. Luo, and Y. Chen, Dilemma of Sewage Sludge Treatment and Disposal in China. Environmental Science \& Technology, 2015. 49(8): p. 4781-4782.

12. S. Donatello and C.R. Cheeseman, Recycling and recovery routes for incinerated sewage sludge ash (ISSA): A review. Waste Management, 2013. 33(11): p. 2328-2340.

13. H. Zhou, A. Meng, Y. Long, Q. Li, and Y. Zhang, A review of dioxin-related substances during municipal solid waste incineration. Waste Management, 2015. 36: p. 106-118.

14. F. Cheng, H. Luo, L. Hu, B. Yu, Z. Luo, and M. Fidalgo de Cortalezzi, Sludge carbonization and activation: From hazardous waste to functional materials for water treatment. Journal of Environmental Chemical Engineering, 2016. 4(4, Part A): p. 4574-4586.

15. F. Cheng, H. Luo, and L.M. Colosi, Slow pyrolysis as a platform for negative emissions technology: An integration of machine learning models, life cycle assessment, and economic analysis. Energy Conversion and Management, 2020. 223: p. 113258.

16. F. Cheng, A.A. Small, and L.M. Colosi, The levelized cost of negative $\mathrm{CO}_{2}$ emissions from thermochemical conversion of biomass coupled with carbon capture and storage. Energy Conversion and Management, 2021. 237: p. 114115.

17. J. Paz-Ferreiro, A. Nieto, A. Méndez, M.P. Askeland, and G. Gascó, Biochar from Biosolids Pyrolysis: A Review. International Journal of Environmental Research and Public Health, 2018. 15(5).

18. G. Bidini, F. Fantozzi, P. Bartocci, B. D‘Alessandro, M. D`Amico, P. Laranci, E. Scozza, and M. Zagaroli, Recovery of precious metals from scrap printed circuit boards through pyrolysis. Journal of Analytical and Applied Pyrolysis, 2015. 111: p. 140-147.

19. Z. Liu and G. Han, Production of solid fuel biochar from waste biomass by low temperature pyrolysis. Fuel, 2015. 158: p. 159-165.

20. M.C. Samolada and A.A. Zabaniotou, Comparative assessment of municipal sewage sludge incineration, gasification and pyrolysis for a sustainable sludge-to-energy management in Greece. Waste Management, 2014. 34(2): p. 411-420. 
21. Q. Yang, H. Zhou, P. Bartocci, F. Fantozzi, O. Mašek, F.A. Agblevor, Z. Wei, H. Yang, H. Chen, X. Lu, G. Chen, C. Zheng, C.P. Nielsen, and M.B. McElroy, Prospective contributions of biomass pyrolysis to China's 2050 carbon reduction and renewable energy goals. Nature Communications, 2021. 12(1): p. 1698.

22. F. Cheng, M.D. Porter, and L.M. Colosi, Is hydrothermal treatment coupled with carbon capture and storage an energy-producing negative emissions technology? Energy Conversion and Management, 2020. 203: p. 112252.

23. J.B. Guinée and E. Lindeijer, Handbook on life cycle assessment: operational guide to the ISO standards. Vol. 7. 2002: Springer Science \& Business Media.

24. G. Thomassen, M. Van Dael, S. Van Passel, and F. You, How to assess the potential of emerging green technologies? Towards a prospective environmental and techno-economic assessment framework. Green Chemistry, 2019. 21(18): p. 4868-4886.

25. N.-Y. Wang, C.-H. Shih, P.-T. Chiueh, and Y.-F. Huang, Environmental effects of sewage sludge carbonization and other treatment alternatives. Energies, 2013. 6(2): p. 871-883.

26. Y. Cao and A. Pawłowski, Life cycle assessment of two emerging sewage sludge-to-energy systems: evaluating energy and greenhouse gas emissions implications. Bioresource technology, 2013. 127: p. 8191.

27. H. Yoshida, T.H. Christensen, and C. Scheutz, Life cycle assessment of sewage sludge management: a review. Waste Management \& Research, 2013. 31(11): p. 1083-1101.

28. H. Luo, F. Cheng, L. Huelsenbeck, and N. Smith, Comparison between conventional solvothermal and aqueous solution-based production of UiO-66- $\mathrm{NH}_{2}$ : Life cycle assessment, techno-economic assessment, and implications for $\mathrm{CO}_{2}$ capture and storage. Journal of Environmental Chemical Engineering, 2021. 9(2): p. 105159.

29. G. Wernet, C. Bauer, B. Steubing, J. Reinhard, E. Moreno-Ruiz, and B. Weidema, The ecoinvent database version 3 (part I): overview and methodology. The International Journal of Life Cycle Assessment, 2016. 21(9): p. 1218-1230. 
30. Appendix 4 Method for Estimating the Change in Mineral Soil Organic Carbon Stocks from Biochar Amendments: Basis for Future Methodological Development. . Available from: https://www.ipccnggip.iges.or.jp/public/2019rf/pdf/4_Volume4/19R_V4_Ch02_Ap4_Biochar.pdf.

31. J. Ifthikar, J. Wang, Q. Wang, T. Wang, H. Wang, A. Khan, A. Jawad, T. Sun, X. Jiao, and Z. Chen, Highly efficient lead distribution by magnetic sewage sludge biochar: sorption mechanisms and bench applications. Bioresource technology, 2017. 238: p. 399-406.

32. Y. Ma, L. Yang, L. Wu, P. Li, X. Qi, L. He, S. Cui, Y. Ding, and Z. Zhang, Carbon nanotube supported sludge biochar as an efficient adsorbent for low concentrations of sulfamethoxazole removal. Science of The Total Environment, 2020. 718: p. 137299.

33. M.M. Ibrahim, C. Tong, K. Hu, B. Zhou, S. Xing, and Y. Mao, Biochar-fertilizer interaction modifies Nsorption, enzyme activities and microbial functional abundance regulating nitrogen retention in rhizosphere soil. Science of the Total Environment, 2020. 739: p. 140065.

34. W.M. Faria, C.C.d. Figueiredo, T.R. Coser, A.T. Vale, and B.G. Schneider, Is sewage sludge biochar capable of replacing inorganic fertilizers for corn production? Evidence from a two-year field experiment. Archives of Agronomy and Soil Science, 2018. 64(4): p. 505-519.

35. W. Buss, A. Bogush, K. Ignatyev, and O. Masek, Unlocking the fertilizer potential of waste-derived biochar. ACS Sustainable Chemistry \& Engineering, 2020. 8(32): p. 12295-12303.

36. S. Ali, M. Rizwan, M.F. Qayyum, Y.S. Ok, M. Ibrahim, M. Riaz, M.S. Arif, F. Hafeez, M.I. Al-Wabel, and A.N. Shahzad, Biochar soil amendment on alleviation of drought and salt stress in plants: a critical review. Environmental Science and Pollution Research, 2017. 24(14): p. 12700-12712.

37. B. Singh, B.P. Singh, and A.L. Cowie, Characterisation and evaluation of biochars for their application as a soil amendment. Soil Research, 2010. 48(7): p. 516-525.

38. T. Liu, B. Liu, and W. Zhang, Nutrients and heavy metals in biochar produced by sewage sludge pyrolysis: its application in soil amendment. Polish Journal of Environmental Studies, 2014. 23(1): p. 271-275. 
39. J. Zhang, J. Shao, Q. Jin, X. Zhang, H. Yang, Y. Chen, S. Zhang, and H. Chen, Effect of deashing on activation process and lead adsorption capacities of sludge-based biochar. Science of The Total Environment, 2020. 716: p. 137016.

40. R. Field and M.L. O'Shea, The handling and disposal of residuals from the treatment of urban stormwater runoff from separate storm drainage systems. Waste management \& research, 1994. 12(6): p. 527-539.

41. E.A. Laws and C.B. Allen, Water quality in a subtropical embayment more than a decade after diversion of sewage discharges. 1996. 